\title{
Non-contrast coronary magnetic resonance angiography: current frontiers and future horizons
}

\author{
Yoko Kato $^{1}$ - Bharath Ambale-Venkatesh ${ }^{2} \cdot$ Yoshimori Kassai $^{3} \cdot$ Larry Kasuboski $^{4} \cdot$ Joanne Schuijf $^{4} \cdot$ Karan Kapoor $^{1}$. \\ Shelton Caruthers ${ }^{4}$. Joao A. C. Lima ${ }^{1}$ (1)
}

Received: 4 October 2019 / Revised: 22 January 2020 / Accepted: 29 January 2020 / Published online: 2 April 2020

(c) The Author(s) 2020

\begin{abstract}
Coronary magnetic resonance angiography (coronary MRA) is advantageous in its ability to assess coronary artery morphology and function without ionizing radiation or contrast media. However, technical limitations including reduced spatial resolution, long acquisition times, and low signal-to-noise ratios prevent it from clinical routine utilization. Nonetheless, each of these limitations can be specifically addressed by a combination of novel technologies including super-resolution imaging, compressed sensing, and deep-learning reconstruction. In this paper, we first review the current clinical use and motivations for non-contrast coronary MRA, discuss currently available coronary MRA techniques, and highlight current technical developments that hold unique potential to optimize coronary MRA image acquisition and post-processing. In the final section, we examine the various research-based coronary MRA methods and metrics that can be leveraged to assess coronary stenosis severity, physiological function, and atherosclerotic plaque characterization. We specifically discuss how such technologies may contribute to the clinical translation of coronary MRA into a robust modality for routine clinical use.
\end{abstract}

Keywords Magnetic resonance coronary angiography $\cdot$ Image acceleration technique $\cdot$ Image denoising $\cdot$ Review article

$\begin{array}{ll}\text { Abbreviations } \\ \text { MRA } & \text { Magnetic resonance angiography } \\ \text { CAD } & \text { Coronary artery disease } \\ \text { CTA } & \text { Computed tomography angiography } \\ \text { CAG } & \text { Coronary angiography } \\ \text { LGE } & \text { Late gadolinium enhancement } \\ \text { ECG } & \text { Electrocardiography } \\ \text { SSFP } & \text { Steady-state free precession } \\ \text { RCA } & \text { Right coronary artery } \\ \text { SNR } & \text { Signal-to-noise ratio } \\ \text { CNR } & \text { Contrast-to-noise ratio } \\ \text { bSSFP } & \text { Balanced steady-state free precession } \\ & \text { imaging }\end{array}$

Joao A. C. Lima

jlima@jhmi.edu

1 Division of Cardiology, Johns Hopkins University School of Medicine, $600 \mathrm{~N}$ Wolfe St, Blalock 524, Baltimore, MD 21287-0409, USA

2 Division of Radiology, Johns Hopkins University, Baltimore, MD, USA

3 Canon Medical Systems Corporation, Otawara, Japan

4 Canon Medical Research USA, Inc., Cleveland, OH, USA

$\begin{array}{ll}\text { FLASH } & \text { Fast low angle shots } \\ \text { MRI } & \text { Magnetic resonance imaging } \\ \text { SR } & \text { Super-resolution } \\ \text { BM3D } & \text { Block matching and 3-D filtering } \\ \text { TNRD } & \text { Trainable nonlinear reaction diffusion } \\ \text { DnCNNs } & \text { Denoising convolutional neural networks } \\ \text { PI } & \text { Parallel imaging } \\ \text { CS } & \text { Compressed sensing } \\ \text { SENSE } & \text { Sensitivity encoding } \\ \text { iGRASP } & \text { Iterative golden-angle radial sparse parallel } \\ & \text { MRI } \\ \text { SPIRiT } & \text { Self-consistent parallel imaging } \\ & \text { reconstruction } \\ \text { ESPIRiT } & \text { Eigenvector maps self-consistent parallel } \\ & \text { imaging reconstruction } \\ \text { tGA } & \text { Tiny golden radial } \\ \text { DLR } & \text { Deep learning reconstruction } \\ \text { XD-GRASP } & \text { Extra-dimensional GRASP } \\ \text { PC } & \text { Phase contrast } \\ \text { CBF } & \text { Coronary blood flow } \\ \text { LAD } & \text { Left anterior descending } \\ \text { LCX } & \text { Left circumflex } \\ \text { CFR } & \text { Coronary flow reserve }\end{array}$




$\begin{array}{ll}\text { MPRAGE } & \begin{array}{l}\text { Magnetization-prepared rapid acquisition } \\ \text { with gradient echo }\end{array} \\ \text { HIP } & \text { High-intensity plaque } \\ \text { UTE } & \text { Ultrashort echo time }\end{array}$

\section{Background}

The diagnosis and management of coronary artery disease (CAD) and consequent myocardial ischemia are central to the prevention of future cardiac events. In this regard, the main advantage of non-contrast coronary magnetic resonance angiography (coronary MRA) is its ability to assess coronary artery morphology and function without ionizing radiation or contrast media. Despite the early recognition of such extraordinary potential [1], significant technical limitations including reduced spatial resolution, long acquisition time, and low signal-to-noise ratio impairing image quality have caused coronary MRA to be less preferred than competing non-invasive techniques such as coronary computed tomography angiography (CTA), and prevented it from routine clinical utilization [2, 3]. However, despite these technical limitations, coronary MRA has contributed significantly to our current understanding of CAD pathophysiology [4, 5] by providing insights into coronary artery distensibility in response to stress [6], plaque characteristics [7], and plaque inflammation [8]. Its usefulness as a non-invasive research method to assess CAD in different groups of patients has been demonstrated not only in single center clinical investigations [9, 10], but also in multi-center studies [11, 12]. Moreover, coronary MRA has proven to be important in the delineation of congenital coronary abnormalities, for which it is recommended as the clinical modality of choice, particularly when there is concern about the use of radiation and contrast $[13,14]$. Recent developments in magnetic resonance imaging are poised to specifically impact coronary MRA in its ability to assess coronary anatomy and function in patients with chest pain or other clinical manifestations that suggest the presence of CAD [15-18]. More recently, the possibility of using deep learning techniques to enhance image quality in applications characterized by low signalto-noise ratios has opened additional avenues of potential development in coronary MRA imaging $[19,20]$. In this paper, we will first review the current clinical status of noncontrast coronary MRA, and then discuss current technical efforts to optimize coronary MRA image acquisition and post-processing. In the last section of this paper, we will discuss the various techniques of coronary anatomical and functional assessment on MRI that when combined together promise diagnostic and prognostic performance boost. Through these discussions, we hope to guide the readers to realize the promise of coronary MRA as a diagnostic tool for clinical use.

\section{Current status of non-contrast coronary MRA}

\author{
Motivations for the clinical use of non-contrast \\ coronary MRA
}

CAD remains the leading cause of death in the world [21]. Catheter-based X-ray coronary angiography (CAG) is the current gold standard for the diagnosis of significant ( $>50 \%$ diameter stenosis) CAD. However, around half of the patients referred for diagnostic CAG do not have significant stenosis [22-24], yet are exposed to ionizing radiation and contrast media as well as the potential risks associated with this invasive procedure [25]. The discomfort of patients during the invasive procedure is also not negligible. Non-contrast coronary MRA is an attractive option for anatomical coronary artery assessment in this regard, albeit relatively underdeveloped compared to coronary CTA. However, there are advantages non-contrast coronary MRA holds over CTA that may be leveraged as the technique matures including: (1) "one-stop-shop-test" by combining it with additional anatomical and functional MRI methods, (2) robustness to the calcium "blooming" that hampers CTA assessment, and (3) absence of ionizing radiation or contrast media exposure [9].

There are several well-defined patient populations that benefit from these advantages. Pediatric congenital heart disease patients frequently present for evaluation of coronary anatomy post-surgery or suspected coronary anomaly. These pediatric patients require multiple follow-up examinations and thus are good candidates for non-contrast coronary MRA [26]. Albrecht et al. have reported that in a pediatric population with suspected anomalous coronary arteries, coronary MRA provided comparable diagnostic accuracy with coronary CTA in the detection of findings that occurs in proximal to mid main coronary arteries like anomalies, high origin, and inter-arterial course of the coronary arteries, admitting superior visualization with CTA in distal coronary arteries [27]. Meanwhile, drawbacks for coronary MRA in pediatric patients include smaller coronary diameter, high resting heart rate, and difficulty of keeping the same position for a long time as compared to adults. Cardiac MRI with sedation or coronary CTA with its inherently higher spatial resolution may be considered appropriate in some cases [28, 29]. Evaluation of Kawasaki disease is another accepted indication for which coronary MRA is reported to be equivalent to CAG (Fig. 1) [30, 31]. Indeed, coronary MRA is recommended as the clinical modality of choice for these populations in which repeated radiation and contrast exposure are major concerns [13, 14]. The Japanese Circulation Society guidelines for Kawasaki disease in 2013 stipulate 

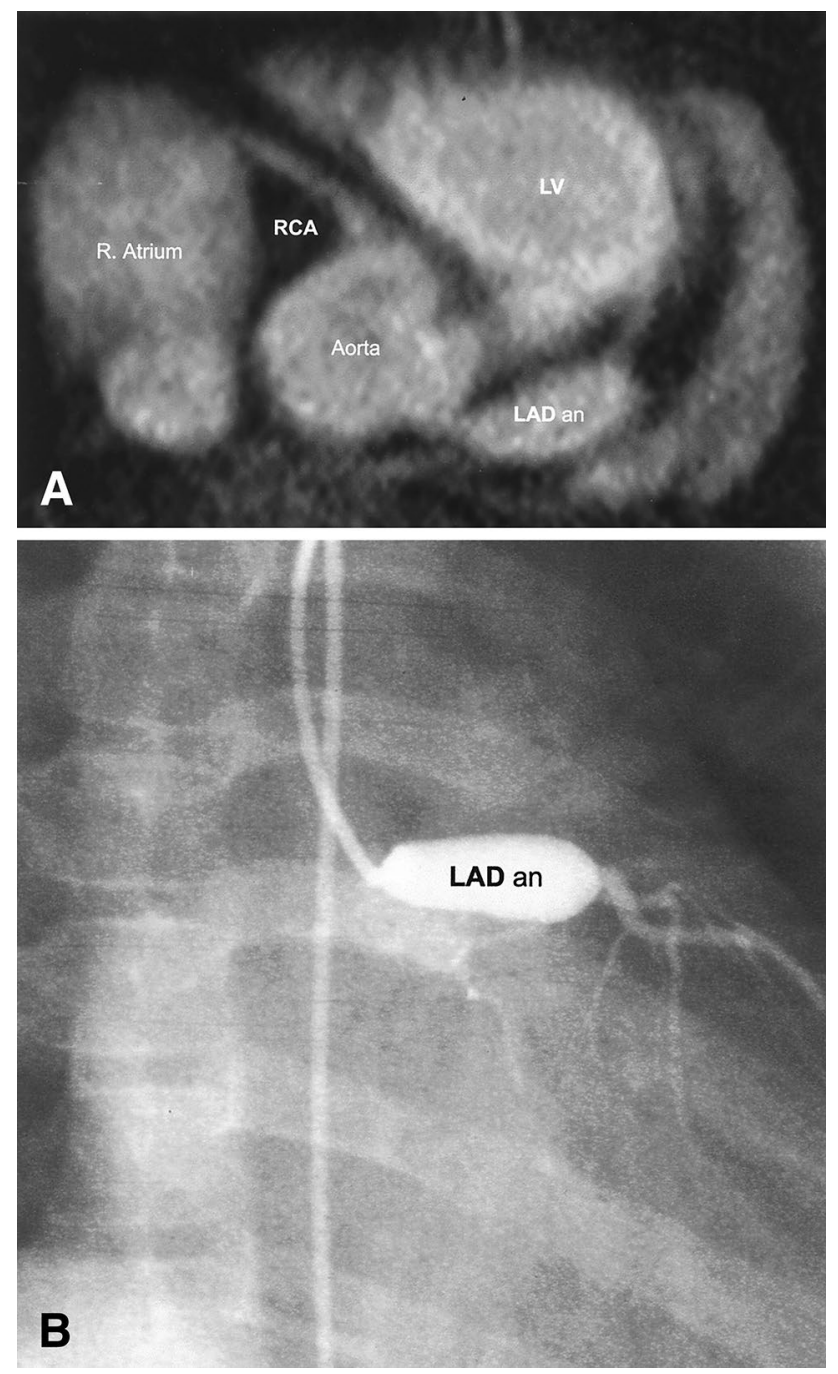

Fig. 1 Coronary MRA (a) and CAG (b) image of a left anterior descending coronary artery aneurysm (LAD an) in a patient with Kawasaki disease. MRA magnetic resonance angiography, $C A G$ coronary angiography, $L A D$ left anterior descending, $L V$ left ventricle, $R$. Atrium right atrium, $R C A$ right coronary artery. (Reprinted with permission from Mavrogeni et al. [30], Copyright (C) 2004 by the American College of Cardiology Foundation)

that coronary MRA is preferred over coronary CTA, as it allows repeated imaging while heart rate control is not required, which enables infants and young children to undergo the examination during sleep [32]. On the other hand, while the European Society of Cardiology guidelines for adult congenital disease published in 2010 recommend regular usage of cardiovascular magnetic resonance when considered superior to echocardiography, these guidelines do admit that CT is superior for non-invasive coronary angiography [33].

In chronic kidney disease (CKD) patients, contrast administration is a major concern due to the risk of postcontrast acute kidney injury after iodine-based contrast media injection [34, 35] or nephrogenic systemic fibrosis after gadolinium-based contrast media [36]. Moreover, these patients often require multiple follow-ups since they frequently present with severely calcified plaques in the coronary arteries. Not only does non-contrast MRCA take away the risk of further kidney injury by contrast injection, but it also allows for coronary lumen visualization without blooming artifacts from calcium as seen in coronary CTA. In MRI, calcifications present very low signal both on T1 and $\mathrm{T} 2$ images due to their low proton density. As a result, coronary calcifications do not obscure the coronary lumen in MRI. Indeed, coronary MRA has been shown to have a better performance in the detection of significant stenosis in patients with moderate to severe calcifications than CTA (Fig. 2) [37].

The principal idea for the treatment strategy of stable CAD is 1) invasive revascularization for the left main stenosis and 2) invasive revascularization when symptoms such as chest pain remain despite optimal medical therapy. Coronary MRA provides information on the distribution and severity of stenotic lesions, which is helpful to assess left main lesions, or when deciding the treatment strategy between percutaneous catheter intervention (PCI) and coronary artery bypass graft (CABG) surgery.

Another recent concern is the possibility of gadolinium depositions in the brain. This phenomenon has been correlated with the number of previous examinations involving gadolinium-based contrast administration [38] and has also been reported in subjects without severe renal dysfunction [39]. Although the long-term effects are not clear, the general consensus is that when possible, reduced exposure to gadolinium is preferable. Non-contrast coronary MRA is in line with this principle.

Meanwhile, coronary MRA has a few major limitations including (1) time-consuming image acquisition which takes around 10-20 min, (2) low spatial resolution (around 1-2 $\mathrm{mm}$ ) compared to coronary CTA (around $0.5 \mathrm{~mm}$ ) or $\mathrm{CAG}(<0.3 \mathrm{~mm})$, (3) poor visualization of coronary stents or calcified plaque due to the low proton density of these elements and limited visibility of the stent lumen due to radiofrequency (RF) shielding effects [40], susceptibility artifacts by diamagnetic (calcium) or ferromagnetic (stent) effect (though manageable with short echo time setting [41]), and (4) no consensus on coronary MRA post-processing and analysis methodology.

As these challenges are tackled and the technique matures, integrated protocols in which coronary MRA is added to other cardiac MRI examinations as a "one-stop-shop-test" are likely to improve the diagnostic and prognostic performance of the MRI examination. For example, the addition of free-breathing whole heart contrast-enhanced coronary MRA at $3 \mathrm{~T}$ to the combination of stress/rest myocardial perfusion imaging and late gadolinium enhancement (LGE) image significantly 

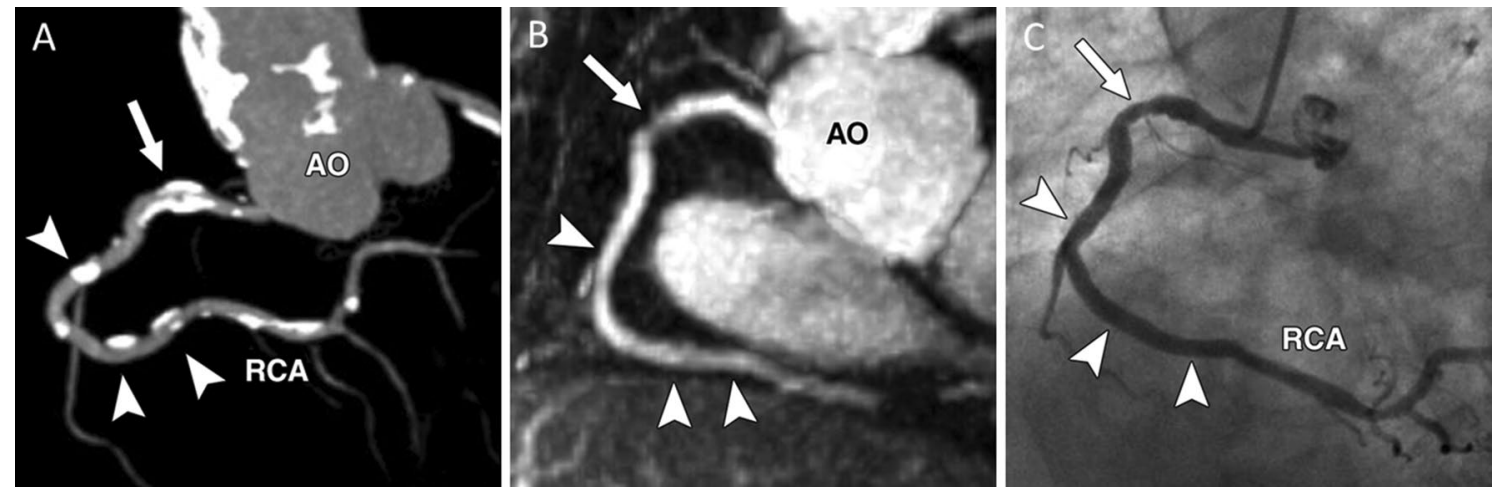

Fig. 2 Representative images of the RCA in three different modalities of a coronary CTA, b coronary MRA, and c CAG. a Diffuse calcification (arrow and arrowheads) was detected in RCA on coronary CTA MIP image. Coronary MRA MIP image $\mathbf{b}$ shows moderate stenosis (arrow, b) and CAG (c) confirms moderate stenosis (arrow, c) in corresponding segment where heavy diffuse calcification can be seen in a (arrow in a). b, c No significant stenosis (arrowheads) in corresponding segments where nodal calcifications are located in (a). $A O$ aorta, $R C A$ right coronary artery, $C T A$ computer tomography angiography, $M R A$ magnetic resonance angiography, $C A G$ coronary angiography, MIP maximum intensity projection. (Reprinted with permission from Liu et al. [37], Copyright (C 2007 by the American Roentgen Ray Society, ARRS)

coverage coronary MRA, requires several preparatory techniques such as electrocardiography (ECG) and respiratory gating [45]. A patient-specific acquisition window is set based on ECG gating during either the diastolic or systolic phase, corresponding to the phase with the least coronary artery motion. For the static phase selection, transaxial cine MR images with a steady-state free precession (SSFP) sequence are acquired prior to the coronary MRA acquisition to evaluate the motion pattern of the right coronary artery (RCA). The dome of the right hemidiaphragm is the preferred location of the respiratory navigator, while the details of navigator implementation tend to be vendor specific [45]. Although the image gets sharper when the ECG and respiratory gating width are narrowed, the inherent disadvantages of narrow windows are a reduction in the data acquisition success rate and a corresponding increase in the image acquisition time, potentially leading to more disturbance from patient motion. In the respiratory navigator, the current general setting of a small gating window of 5-6 mm leads to a low imaging efficiency (30-50\%) [46]. In the absence of overt contraindications, the administration of sublingual nitroglycerin (NTG) is recommended to improve luminal visualization in terms of signal-to-noise ratio (SNR), vessel diameter, and vessel sharpness of the coronary MRA [47]. Heer et al. have reported that the significant increase in coronary diameter and visible vessel length observed with sublingual NTG administration result in improved sensitivity, specificity, and diagnostic accuracy for the detection of $>50 \%$ coronary stenosis on $1.5 \mathrm{~T}$ non-contrast coronary MRA [48].

The current acquisition standard for coronary MRAthree-dimensional (3D) free-breathing whole-heart 


\subsection{T vs. $3 \mathrm{~T}$ coronary MRA}

Coronary MRA at higher magnetic field strengths has been an area of active research given the potential benefits in SNR and contrast-to-noise ratio (CNR) as well as higher spatial and temporal resolutions. The optimal non-contrast coronary MRA imaging technique differs between 1.5 T MRI and 3 T MRI. In 1.5 T-MRI, balanced steady-state free precession imaging (bSSFP) is the most commonly used sequence $[12,45,49]$. However, the applicability of bSSFP to $3 \mathrm{~T}$ MRI is limited for a variety of reasons including (1) more pronounced $\mathrm{B} 0$ and $\mathrm{B} 1$ field inhomogeneities than $1.5 \mathrm{~T}$, (2) degraded image quality and increased magnetic field heterogeneity from RF pulse-induced dielectric effects, and (3) increased power deposition in the human body at $3 \mathrm{~T}$ limits the use of large flip angles for SSFP imaging [50]. To address the above-mentioned challenges, spoiled gradient echo sequences are used [51, 52]. Despite somewhat limited by lower SNR and CNR than SSFP, spoiled gradient echo sequencing, ECG- and diaphragm navigator gating, and fat suppression have become the standard acquisition protocol for non-contrast coronary MRA at $3 \mathrm{~T}$ [15]. In a study that investigated the image quality between SSFP and gradient echo sequence for coronary MRA at $3 \mathrm{~T}$, the image quality was higher and the measured vessel length was longer in gradient echo sequence [53]. When performed with the same sequence, $3 \mathrm{~T}$ coronary MRA is not inferior to $1.5 \mathrm{~T}$ coronary MRA both in image quality and diagnostic accuracy for the detection of coronary stenosis [54].

Figure 3 shows a representative non-contrast coronary MRA case acquired in $3 \mathrm{~T}$ MRI with the conventional image acquisition acceleration method of parallel imaging (PI).

\section{Non-contrast vs. contrast-enhanced coronary MRA}

Non-contrast coronary MRA leverages the natural T2 differences between the blood and the surrounding architectures. Techniques such as fat saturation pre-pulses, magnetization pre-pulses, and $\mathrm{T} 2$ preparatory pulses augment the relative signal of the coronary arteries. These pre-pulses differentiate oxygenated blood in coronary arteries from the surrounding short $\mathrm{T} 2$ relaxation tissues such as cardiac muscle, (a)

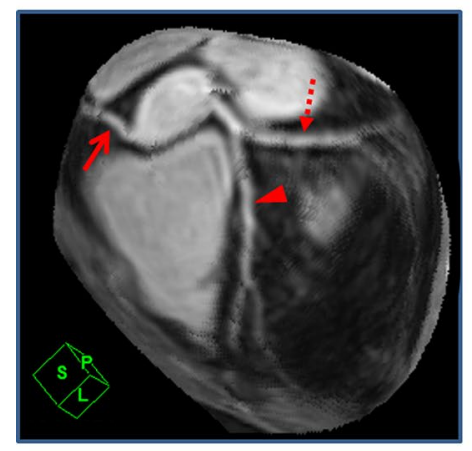

(b)

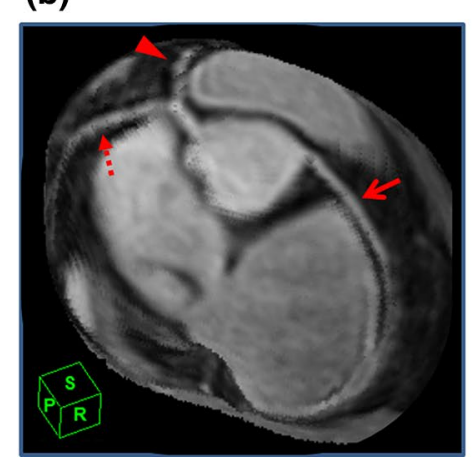

(c)

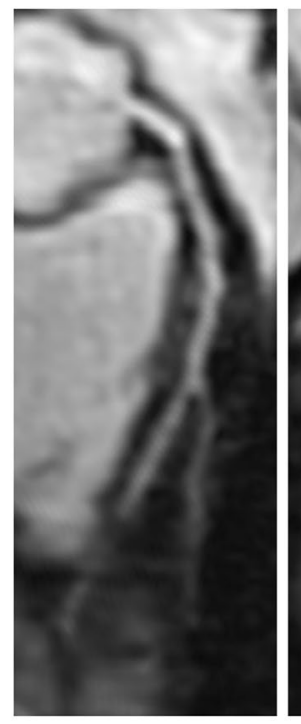

LAD (d)

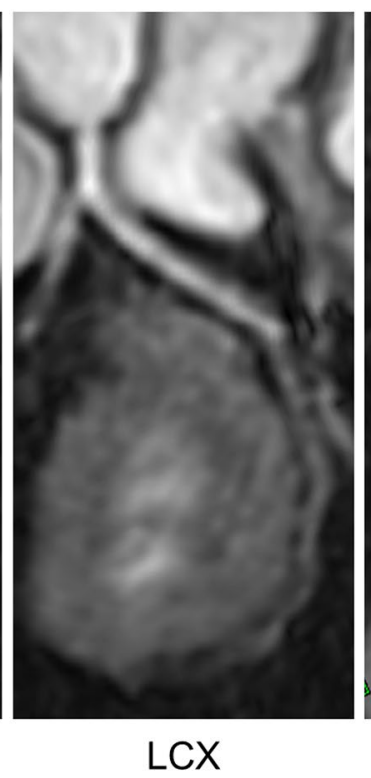

(e)

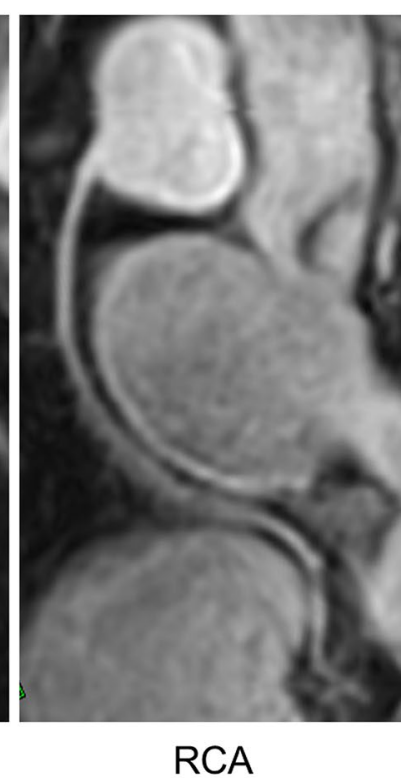

Fig. 3 A representative case of a non-contrast coronary MRA with a conventional technique. A non-contrast coronary MRA acquired in $3 \mathrm{~T}$ scanner with the conventional image acquisition acceleration method of parallel imaging (PI) is presented. A spoiled gradient echo sequence with ECG gating, diaphragm navigator gating, and fat suppression with spectral attenuated inversion recovery was used for the image acquisition. The MRI acquisition parameters were $\mathrm{FOV}=350 \times 350 \mathrm{~mm}$, matrix $=224 \times 232$, slice thick- ness $=1.5 \mathrm{~mm}$, slice number $=80$, acceleration factor $=2.0 \times 2.0$, $\mathrm{TR}=4.9 \mathrm{~ms}, \mathrm{TE}=1.9 \mathrm{~ms}$, flip angle $=12^{\circ}$, bandwidth $=326 \mathrm{~Hz} /$ pix, acquisition voxel size $=1.6 \times 1.5 \times 1.5 \mathrm{~mm}$, reconstructed voxel size $=0.80 \times 0.80 \times 0.75$, navigator gating window $=5 \mathrm{~mm}$. a, b Volume rendering images. Arrowheads: LAD, dashed arrows: LCX, and solid line arrows: RCA. c-e Curved MPR images of c LAD, d LCX, and e RCA. $M R A$ magnetic resonance angiography, $L A D$ left anterior descending, $L C X$ left circumflex, $R C A$ right coronary artery 
deoxygenated blood in cardiac veins, and epicardial fat [55, 56]. Dixon water-fat separation [57] and lipid insensitive binomial off-resonant excitation (LIBRE) [58, 59] (Fig. 4) are also available options for fat suppression on coronary MRA. Another approach to fat suppression, the fast interrupted steady-state (FISS) sequence, uses an RF excitation pulse to natively suppress the fat signal without the need for periodical application of fat suppression and ramp-up pulses, and is reported to present a strong suppression of pericardial fat signal $[60,61]$. The fat suppression technique is more challenging in radial imaging with higher magnetic field strengths, since the field inhomogeneities are typically accentuated. At the current stage, there is no conclusion on which fat suppression technique is the best for the current coronary MRA imaging technique. In comparison to the SSFP sequence acquisition in $1.5 \mathrm{~T}$ MRI, the T1 differences between blood and myocardium are smaller in $3 \mathrm{~T}$ MRI with gradient echo sequence acquisition. Therefore, contrastenhanced coronary MRA was preferred during the period that $3 \mathrm{~T}$ coronary MRA acquisition was under development. With the maturation of the technique, the non-contrast coronary MRA image is more feasible and preferred in $3 \mathrm{~T}$ MRI.
The diagnostic performance of coronary MRA varies between studies, likely a result of the presence or absence of contrast administration, heterogeneity of the acquisition sequences, and the analytic methods used. A meta-analysis of 1638 patients in 24 studies including $1.5 \mathrm{~T}$ and $3 \mathrm{~T}$ coronary MRA studies reported the estimated sensitivity and specificity for detecting $>50 \%$ stenosis is $95 \%$ and $77 \%$ for contrast coronary MRA, while those values were $87 \%$ and $69 \%$, respectively, for non-contrast coronary MRA [3]. The diagnostic performance of $1.5 \mathrm{~T}$ non-contrast coronary MRA to detect $>50 \%$ stenosis, with CAG serving as the reference standard, was reported by Kato et al. in a multicenter trial of 137 patients across seven hospitals in Japan. On a per-patient level, the observed sensitivity and specificity were $88 \%$ and $72 \%$, respectively [12]. Hamdan et al. compared the performance of $3 \mathrm{~T}$ non-contrast coronary MRA against 64-slice coronary CTA to detect significant $\mathrm{CAD}$, using quantitative coronary angiography as the gold standard. On a per-patient basis, the observed sensitivities and specificities were $87 \%$ and $77 \%$ for non-contrast coronary MRA versus $90 \%$ and 83\% for CTA, respectively [10]. Despite the trend toward higher diagnostic accuracy values for CTA, both techniques
Fig. 4 Comparison of the different fat saturation methods on radial trajectories coronary MRA at $3 \mathrm{~T}$ in healthy subjects. Coronary MRA images show the left and right coronary artery system depicting the RCA and the LAD in several subjects. Using the LIBRE pulse the visualization of the RCA and LAD was improved (yellow arrow), as well as fat suppression (orange arrows) compared with FS and WE.

Vessel sharpness as well as imaged vessel length was significantly increased using LIBRE. Window and level are identical in images acquired in each volunteer. MRA magnetic resonance artery, $R C A$ right coronary artery, $L A D$ left anterior descending artery, LIBRE lipid insensitive binomial off-resonant excitation, $F S$ fat saturation, $W E$ water excitation. (Reprinted with permission from Batiaansen et al. [59] Copyright (C) 2019 by the Authors)
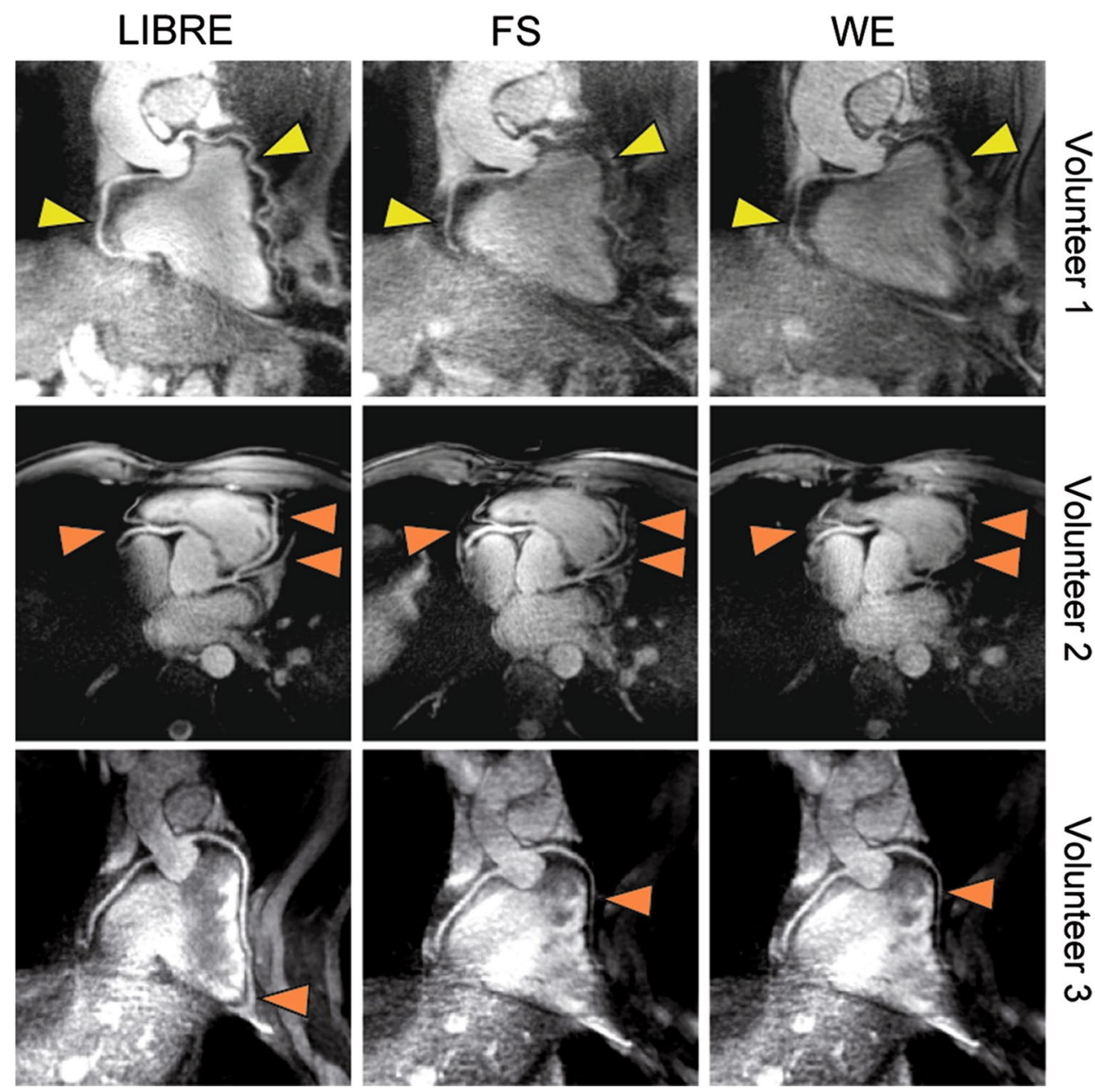

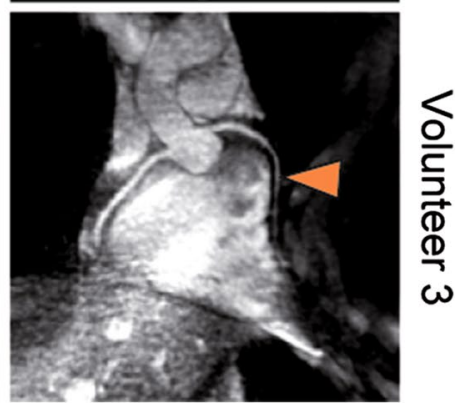


were equal in their ability to identify patients who subsequently underwent revascularization. Current diagnostic performance of non-contrast coronary MRA is encouraging, but not as high as contrast coronary MRA and coronary CTA. However, as discussed earlier, the various advantages of non-contrast coronary MRA make it exceedingly attractive in many clinical situations. Technical developments provide further promise to improve the diagnostic performance of non-contrast coronary MRA.

\section{Current in-progress topics in coronary MRA}

The major challenges of current coronary MRA sequences remain in: (1) unpredictable and long scan times mainly due to low gating efficiency which need image acquisition acceleration techniques including trajectory design, sparse sampling, and reconstruction; (2) residual respiratory motion artifacts due to simplified motion models and translational motion correction only. Advanced non-rigid motion correction techniques can address not only the motion artifacts but the low gating efficiency problem by allowing for $100 \%$ scan efficiency; and (3) overall image quality problems including those that may be solved by resolution improvement and denoising. Table 1 is a summary of the current technical challenges facing wider adoption of coronary MRA and corresponding solutions offered by current techniques and promising techniques under development which are discussed in the following paragraphs.

\section{Image acquisition acceleration technique (1): trajectory design and sparse sampling}

Trajectory design of k-space sampling method is the first step of the image acquisition acceleration strategy and it is closely related with the subsequent reconstruction strategy. Cartesian k-space sampling is the most widely used trajectory design in current MRI image and in coronary MRA

Table 1 Summary of technical challenges on coronary MRA and corresponding solutions with current and promising techniques

\begin{tabular}{|c|c|c|c|c|}
\hline \multirow[t]{2}{*}{ Problems } & \multicolumn{2}{|l|}{ Current techniques } & \multicolumn{2}{|l|}{ Promising techniques } \\
\hline & Methods & Characteristics & Methods & Characteristics \\
\hline $\begin{array}{l}\text { 1. Time-consuming image } \\
\text { acquisition }\end{array}$ & $\begin{array}{l}\text { Parallel imaging (PI) } \\
\text { [80-84] }\end{array}$ & $\begin{array}{l}\text { Well-established method } \\
\text { Limitation of the accelera- } \\
\text { tion factor } \\
\text { Characteristic artifacts }\end{array}$ & $\begin{array}{l}\text { Compressed Sensing }(\mathrm{CS}) \\
{[15,16,85,86]}\end{array}$ & $\begin{array}{l}\text { Potentially more effective in } \\
\text { higher-dimensional image } \\
(3 \mathrm{D}>2 \mathrm{D}) \text { which is ideal } \\
\text { for 3D coronary MRA } \\
\text { acquisition } \\
\text { Further techniques that } \\
\text { combine PI and CS [65, } \\
78,88-91] \text { or sparse } \\
\text { k-space acquisition and } \\
\text { DL [92, 93] are potentially } \\
\text { available }\end{array}$ \\
\hline $\begin{array}{l}\text { 2. Low scan efficiency } \\
\text { from respiratory and } \\
\text { ECG gating }\end{array}$ & $\begin{array}{l}\text { Respiratory and ECG } \\
\text { gating are the current } \\
\text { standard technique }\end{array}$ & $\begin{array}{l}\text { Strict gating gives better } \\
\text { image quality but trade- } \\
\text { off with long acquisition } \\
\text { time }\end{array}$ & $\begin{array}{l}\text { Self-gating with motion } \\
\text { correction }[17,46,75, \\
94-98] \\
\text { Golden-angle image acqui- } \\
\text { sition and reconstruction } \\
{[18,71,72,91]}\end{array}$ & $\begin{array}{l}\text { No need for respiratory gat- } \\
\text { ing or ECG gating } \\
\text { Simultaneously acquired } \\
\text { CINE images } \\
\text { Time consuming for the } \\
\text { reconstruction }\end{array}$ \\
\hline 3. Low resolution & $\begin{array}{l}\text { Sub-millimeter spatial } \\
\text { resolution acquisition } \\
\text { [84] }\end{array}$ & Trade-off with SNR & $\begin{array}{l}\text { Super-resolution with } \\
\text { inter-slice reconstruction } \\
\text { [99] } \\
\text { Super-resolution based on } \\
\text { overcomplete dictionar- } \\
\text { ies [100, 104] } \\
\text { Super-resolution based on } \\
\text { deep learning [101, 102] }\end{array}$ & $\begin{array}{l}\text { Inter-slice reconstruction } \\
\text { method works well with } \\
2 \mathrm{D} \text { images }\end{array}$ \\
\hline 4. Noise & $\begin{array}{l}\text { Mathematical denoising } \\
{[108,109]}\end{array}$ & $\begin{array}{l}\text { No generally accepted } \\
\text { standard for clinical use } \\
\text { for any commercial filter }\end{array}$ & $\begin{array}{l}\text { DL denoising }[19,20 \text {, } \\
113-116,140]\end{array}$ & $\begin{array}{l}\text { Better preservation of the } \\
\text { edge } \\
\text { Potentially works well with } \\
\text { specific situation such as } \\
\text { coronary MRA-dedicated } \\
\text { denoising }\end{array}$ \\
\hline
\end{tabular}

$M R A$ magnetic resonance angiography, SNR signal-to-noise ratio, $D L$ deep learning, $P I$ parallel imaging, $C S$ compressed sensing, ECG electrocardiography 
as well. The conversion from $\mathrm{k}$-space domain to the image domain is simple with the inverse fast Fourier transform (FFT). Meanwhile, other types of non-Cartesian trajectory designs like radial and spiral trajectories have several advantages in the aspect of accelerated image acquisition and are of great interest. Reconstruction from non-Cartesian trajectories generally use filtered back-projection [62] or interpolation to the Cartesian grid k-space [17, 18, 63-65] so that the conversion to the image domain is more complicated.

Radial and spiral-like Cartesian trajectories have undersampling properties to create incoherent noise-like artifacts, which are a requirement for compressed sensing (CS) or low-rank reconstructions while still allowing for much shorter reconstruction times compared to non-Cartesian trajectories [65-69]. These techniques have been extensively used in recent coronary MRA studies.

Non-Cartesian trajectories can sample denser in the center of the k-space referring their design. This is preferable to image coronary MRA (1) to achieve faster acquisition with sparse $\mathrm{k}$-space sampling and (2) to address motion artifact by average effect [70-72] or (3) to extract motion signals for self-navigation or motion compensation [46, 73-75]. "Golden-angle" radial sampling [76] is a good example of non-Cartesian trajectory. This design brings approximately uniform k-space coverage for many useful subsets of acquired data, which enables dynamic imaging studies with continuous data acquisition and retrospective reconstruction of image series with flexible temporal resolution by grouping a different number of consecutive measurements into each temporal frame [77, 78]. Furthermore, the "stack-of-stars" $k$-space sampling is the hybrid of golden-angle radial trajectories with Cartesian sampling. By combined application of parallel imaging to the Cartesian sampling direction and compressed sensing to the remaining directions for the reconstruction, streaking artifacts can be mostly removed with improved delineation of fine structures using the proposed strategy [71, 78, 79]. In the following discussion on reconstruction and motion correction techniques, the relevant trajectory designs are discussed together.

\section{Image acquisition acceleration technique (2): reconstruction (parallel imaging and compressed sensing)}

Sparse k-space sampling which violates the Nyquist sampling theorem is central to accelerated image acquisition. Two major reconstruction methods are parallel imaging (PI) and CS, which are in practice combined to achieve highly accelerated acquisition.

Parallel imaging (PI) is currently the most widely used method for image acquisition acceleration. PI approaches share the following characteristics: (1) undersampled k-space data in the phase-encoding direction (and partition-encoding direction in 3D imaging), (2) data acquisition with an array of independent receiver channels instead of using a large homogenous volume receive coil, and (3) usage of a dedicated algorithm, which requires some knowledge of the individual coil sensitivities, to combine the undersampled data [80-83]. Gharib et al. have reported that PI combined with high-resolution coronary MRA results in shortened image acquisition times with preserved image quality [84]. Drawbacks of PI include the limitation of the maximum acceleration factor caused by the number of receiver channels and specific artifacts, such as residual aliasing and $\mathrm{g}$-factor noise enhancement [83].

CS is a promising image acquisition acceleration method that works more efficiently in higher dimensional images such as 3D images or images with a temporal dimension. The key components of CS are: (1) image sparsity or transform sparsity, (2) pseudo-random undersampling, and (3) iterative nonlinear reconstruction [85]. CS reconstructions require prior optimization of a regularization parameter, or data consistency tuning constant, to find the best trade-off between the data consistency and sparsity terms [85]. Sparse and random sampling in multi-dimensional data sets result in 'noise-like' incoherence artifacts unlike coherence artifacts seen in PI without random sampling [86]. These incoherence artifacts can be reduced within the CS reconstruction, providing an ideal condition for 3D coronary MRA image acquisition. Coronary MRA acquired with CS has shown comparable image quality with PI-coronary MRA, yet with shortened image acquisition time [15]. Akçakaya et al. have compared conventional PI and CS combined with LOST de-aliasing strategy [87] for sub-millimeter wholeheart coronary MRA. Overall image quality and perceived (semi-quantitative) SNR of the CS images were significantly higher than those of conventional PI [16].

Further image acceleration methods which combine CS with PI such as the k-t sparse technique with sensitivity encoding (SENSE) reconstruction [88], iterative Goldenangle RAdial Sparse Parallel MRI (iGRASP) [78], selfconsistent parallel imaging reconstruction (SPIRiT) [65] and parallel imaging using eigenvector maps (ESPIRiT) [89] are areas of active research. SPIRiT and ESPIRiT are able to incorporate an L1-norm minimization term to additionally enforce sparsity in a transform domain, which has the same underlying theory as CS [90]. Haris et al. have reported high quality of images with iGRASP in comparison to the PI-based real-time imaging in the cardiac and extra-cardiac structure visibility in fetal cardiac examinations [91].

\section{Image acquisition acceleration technique (3): reconstruction (deep learning (DL))}

Another approach is deep learning reconstruction from the subsampled k-space data. In a recent CS combined with DL 
approach, successful reconstruction was achieved from $29 \%$ of the k-space data with comparable image quality to fully sampled MRI reconstructions [92]. Combining tiny goldenangle radial sampling (tGA) with DL resulted in more than five times faster overall reconstruction time, superior image quality, and better accuracy of biventricular volumes than iGRASP when compared in short axis cine image. The total reconstruction time for all the short axis cine slices was $22.0 \mathrm{~s}$ with this method, which allowed for the real-time image reconstruction [93]. These advanced techniques all hold great potential for use in coronary MRA image acquisition acceleration and reconstruction, although there is no current consensus on which technique is most favorable. The central thesis is that the combination of PI and CS is expected to afford high spatial resolution while reducing the total time of acquisition. Additionally, deep learning reconstruction (DLR) promises effective denoising to improve SNR and CNR. Figure 5 shows a comparison between PI, CS, and CS processed with DLR.

\section{Motion correction}

ECG gating and respiratory gating is the most widely used motion correction method. Its drawbacks are the low efficiency of data acquisition resulting in unpredictable and long scan times despite the need for expert planning. This respiratory gating method prospectively corrects for translational motion of the heart in the superior-inferior direction, while it does not account for remaining directions, or rotations or nonrigid deformations.

Several promising techniques are being investigated that aim to improve the motion artifact as well as the scan efficiency. One promising approach is a self-navigator derived from the imaging data itself [73]. Such self-gating methods including 2D and 3D image navigators have been first introduced for 3D single heart phase coronary MRA [94, 95].

When combined with 3D affine or 3D non-rigid reconstruction, this approach can achieve $100 \%$ scan efficiency [17, 46, 96-98] (Fig. 6). Bhat et al. have investigated a whole-heart coronary MRA acquisition method with $100 \%$ scan efficiency reconstructed with respiratory motion correction. They used the navigator signal as a reference respiratory signal to segment the data into six respiratory bins. The reconstruction of low-resolution undersampled images for each respiratory bin was enabled from the 3D projection reconstruction k-space acquisition, which samples data on a spiral path running on the surface of a sphere. The data from different respiratory bins were retrospectively combined after motion correction based on the affine transform. When compared with a traditional navigator gating approach, their method reduced scan time by a factor of 2.5 while image quality was preserved [46]. Piccini et al. have reported that respiratory self-navigation with $100 \%$ acceptance rate significantly reduced the acquisition time from $16.23 \pm 6.28$ to $6.07 \pm 0.57 \min (p<0.01)$ when compared with the navigator-gated coronary MRA acquisition [96]. In addition, the authors reported that the end-expiratory reference position significantly improved the image quality as compared to using end inspiration as a reference [97].

Another promising approach toward motion correction is the continuous $3 \mathrm{D}$ golden-angle radial sampling and reconstruction of separated cardiac and respiratory dimensions $[18,71,72]$. These methods have the advantage (a)

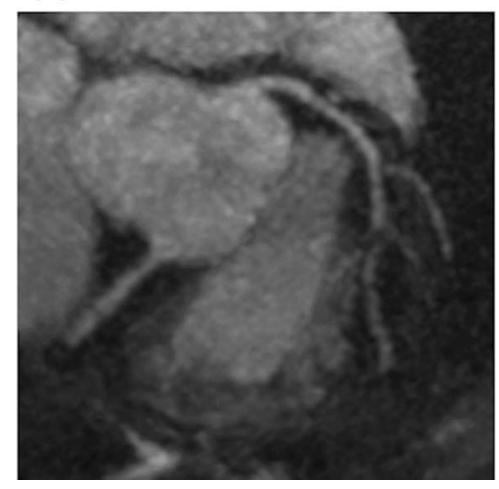

(b)

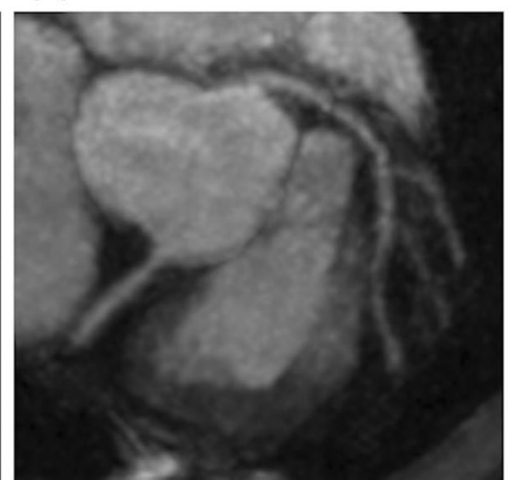

(c)

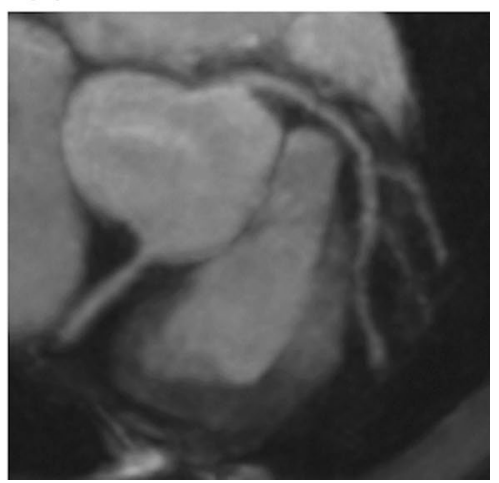

Fig. 5 Coronary MRA images of PI, CS, and CS with deep learning reconstruction. Three MPR images with identical resolution yet different image acceleration methods and post-processing are shown. a PI. b CS. c CS with deep learning reconstruction postprocessing. c The best image quality among the three images. The PI and CS images were acquired with a spoiled gradient echo sequence with ECG-gating, diaphragm navigator gating, and fat suppression with spectral attenuated inversion recovery. The MRI acquisi- tion parameters were $\mathrm{FOV}=380 \times 380 \mathrm{~mm}$, Matrix $=392 \times 384$, slice thickness $=1.0 \mathrm{~mm}$, slice number $=152$, acceleration factor $=2.0 \times 2.0, \mathrm{TR}=5.3 \mathrm{~ms}, \mathrm{TE}=2.0 \mathrm{~ms}$, flip angle $=12$ degree, bandwidth $=279 \mathrm{~Hz} /$ pix, acquisition voxel size $=1.0 \times 1.0 \times 1.0 \mathrm{~mm}$, reconstructed voxel size $=0.5 \times 0.5 \times 0.5 \mathrm{~mm}$, navigator gating window $=4 \mathrm{~mm}$. For the DLR technique, see Refs. [116, 140]. MRA magnetic resonance angiography, $P I$ parallel imaging, $C S$ compressed sensing, $M P R$ multiplanar reconstruction 
(a)

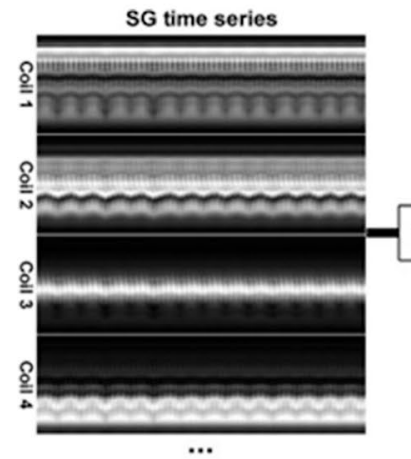

$\cdots$

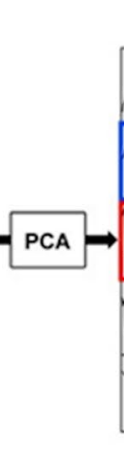

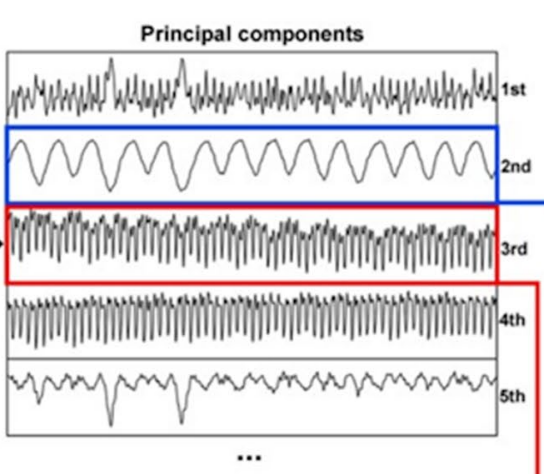

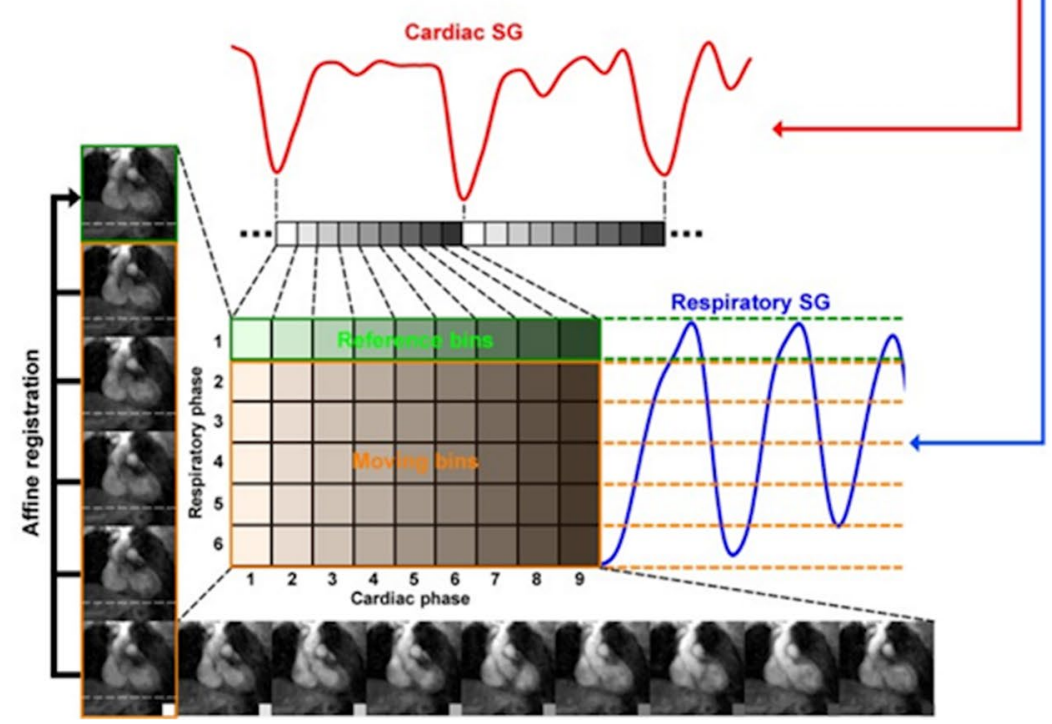

(b)

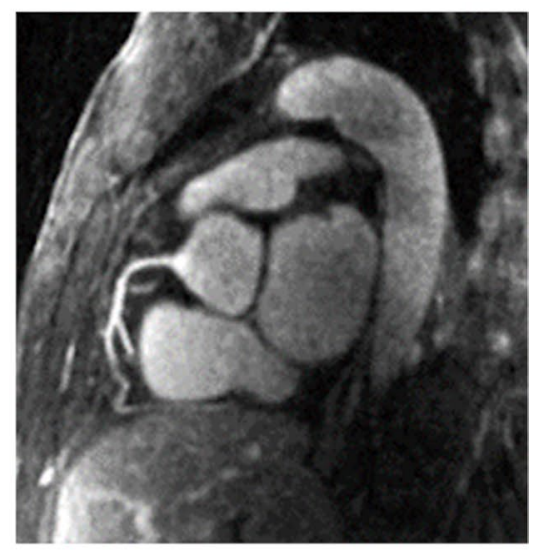

Fig. 6 Schematics of the proposed self-gating, data binning, and respiratory motion correction framework. a First, the cardiac and respiratory motion components are identified from the PCA of the multichannel self-gating profile time series. Then, the imaging data are mapped to different cardiac and respiratory bins based on its cardiac and respiratory phase derived from the motion signals. Next, with one common respiratory phase selected as reference (in this example, respiratory phase 1 for cardiac phases 1-9), all other bins (respiratory phases 2-6, cardiac phases 1-9) are registered to the corresponding reference bin of the same cardiac phase using an affine transform

that coronary MRA images can be reconstructed with different temporal resolutions, or, since the images are acquired over the entire cardiac cycle, cine images of other structures can be derived from the same image data [17]. Another advantage is time reduction through elimination of the respiratory gating preparation. Feng et al. used a framework called eXtra-Dimensional GRASP (XDGRASP) [71] which combines a continuous 3D goldenangle radial sampling scheme with a multidimensional compressed sensing technique to reconstruct separated cardiac and respiratory dimensions. The proposed method resulted in higher image quality in the myocardium and coronary arteries, better coronary sharpness, and longer model. The k-space trajectory and data are then modified accordingly for respiratory motion correction. The six images on the left show the six respiratory phases in cardiac phase 1 . The horizontal dashed lines help visualize the SI motion of the heart due to respiration. The nine images on the bottom show the nine cardiac phases in respiratory phase 6 . The contraction of the left ventricle can be clearly seen. b A representative case with excellent depiction of the right coronary artery. PCA principal component analysis. Reprinted with permission from Pang et al. [17] Copyright @ 2014 by the Wiley Periodicals, Inc.

coronary length visualized than respiratory motion-corrected 3D and 4D whole-heart imaging [18]. Haji-Valizadeh et al. have scanned the aorta with an accelerated coronary MRA sequence with stack-of-stars k-space sampling and GRASP reconstruction, achieving comparable image quality as contrast-enhanced conventional imaging with significant scan time reduction $(5: 55 \pm 0: 48 \mathrm{~min}$ vs. $6: 56 \pm 2: 10 \mathrm{~min})$. The mean off-line image reconstruction time was $4 \mathrm{~h} 41 \mathrm{~min}$ and $13 \mathrm{~s}$ [72].

While these methods look promising, their robustness in daily practice with respect to reconstruction with clinically acceptable reconstruction time and motion correction is an ongoing area of research [17]. 


\section{Image quality improvement (1): high-resolution coronary MRA acquisition/super-resolution coronary MRA post-processing}

Coronary MRA image acquisition under free breathing offers the opportunity for improved spatial resolution including sub-millimeter coronary MRA, while there are drawbacks such as increased acquisition times and lower SNR. Gharib et al. acquired high-resolution coronary MRA using 3 T magnetic resonance imaging (MRI) with a voxel size as small as $0.35 \times 0.35 \times 1.5 \mathrm{~mm}^{3}$ and compared the images with coronary MRA images having $0.7 \times 1 \times 3 \mathrm{~mm}^{3}$ voxel size. The higher resolution images showed a $47 \%$ improvement in vessel sharpness, although image acquisition times were longer and SNR and CNR reduced as compared to the lower-resolution coronary MRA [84]. Super-resolution (SR) is a different approach than voxel size adjustment and has been already utilized in brain imaging. There are several methods reported such as inter-slice reconstruction applied to 2D multislice MRI [99], image domain SR via patchbased sparse representation using overcomplete dictionaries [100], and deep learning-based SR [101-103]. In coronary MRA images, dictionary-based super-resolution applied to 1.5 T non-contrast coronary MRA was reported by Ishida et al. [104]. Their SR technique showed significant improvement in the detection of coronary artery stenosis as compared to conventional resolution coronary MRA. Further improvements in acquisition and reconstruction methods are likely to lead to routine high-resolution coronary MRA images.

\section{Image quality improvement (2): denoising/ smoothing}

Coronary MRA image quality is not merely assessed using SNR or image resolution measures. Other metrics are also considered, such as overall visual image quality allowing meaningful clinical diagnosis, the visually recognizable coronary length, and the crispness/sharpness (conspicuity) of the coronary wall edges [15]. Such a comprehensive image quality assessment has traditionally relied on experienced observers, but initial results from deep learning architecture for automated image quality assessment are promising. Efforts are already ongoing in other domains such as liver MRI [105] and in other modalities such as coronary CTA [106], and these developments may be applicable to coronary MRA as well.

Image denoising is an indispensable first step in many practical applications including coronary MRA. It aims to preserve edges while smoothing out the noise. Oversmoothing renders the image blurry, which is problematic in coronary MRA for the interpretation of clinically meaningful findings such as intensity change in the coronary lumen or fine anatomies like distal coronary arteries or branches. Noise may be roughly categorized into additive white Gaussian noise, multiplicable noise (speckle noise), impulse noise (salt and pepper noise), and shot noise (Poisson noise). In MR images, the predominant noise is actually non-Gaussian such as a Rician distribution [107], yet it is a common practice to assume noise as Gaussian since Rician noise asymptotically becomes Gaussian for high SNR [107]. Some denoising techniques aim to cover a wide range of noise models such as Gaussian and non-Gaussian noise [108, 109]. In the paragraphs below we discuss two denoising approaches, namely (1) conventional methods and (2) deep learning approaches applicable for coronary MRA imaging.

\section{Conventional methods}

There is no generally accepted standard for clinical/commercial application of any denoising filter. Denoising filters applied to coronary MRA images need to be carefully considered, with regard to the balance between preserving the detailed coronary information and strength of denoising. Most traditional spatial filtering techniques directly operate on pixels in the image (or spatial) domain and have a tendency to blur the edges, which is not preferred in coronary imaging. In contrast, transform domain filtering operates on the wavelet transformed data and then transforms it back to the spatial domain, leading to faster computation and preserved edge-detail fidelity based on at least one prior report [110]. Most filtering techniques assume an equal noise distribution across the image, although spatially varying noise levels occur such as those obtained by parallel imaging. In such cases, spatially adaptive non-local denoising may provide better results [108]. One example of such denoising methods and the current state of the-art is block matching and 3-D filtering (BM3D) [109]. That method groups similar patches into blocks, transforms them to wavelet coefficients, then thresholds to obtain an optimal representation, and transforms back. BM3D can be adapted to various noise models such as additive noise and non-Gaussian noise.

\section{Deep learning approaches}

Deep learning reconstruction does not require modeling of noise. It has the ability to perform improved denoising through efficient optimization of the denoising level and good edge preservation based on the characteristics of "learning noise" strategy, which works well on coronary MRA images (Fig. 7). Consequently, denoising with deep learning may achieve higher SNR values than conventional filters (Fig. 7). Another characteristic is its flexibility with various frameworks, including application to the image domain as well as the k-space domain to create either denoised spatial images or denoised k-space data $[111,112]$. 
(a)

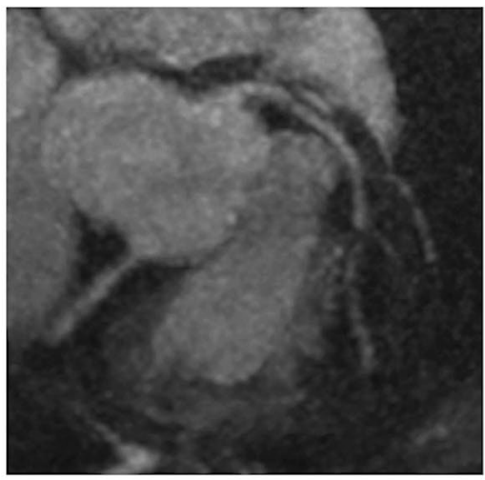

(d)

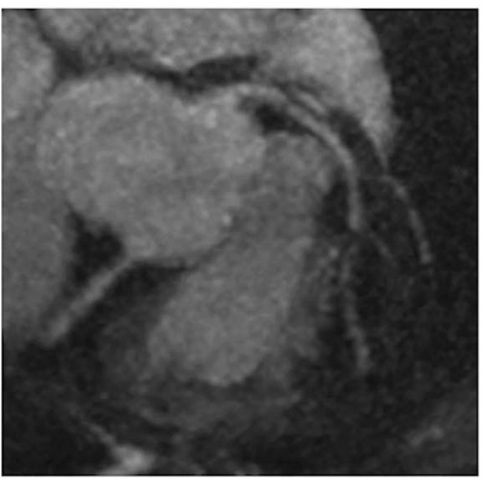

(b)

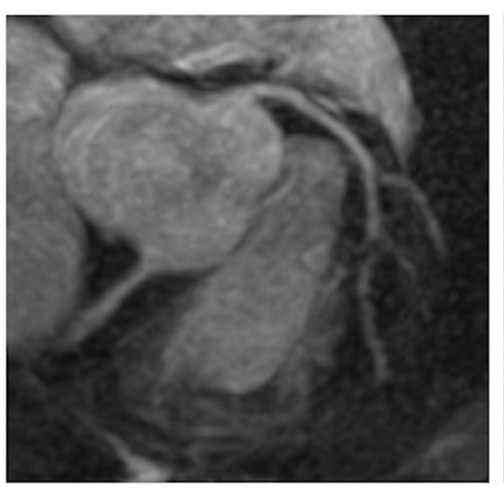

(e)

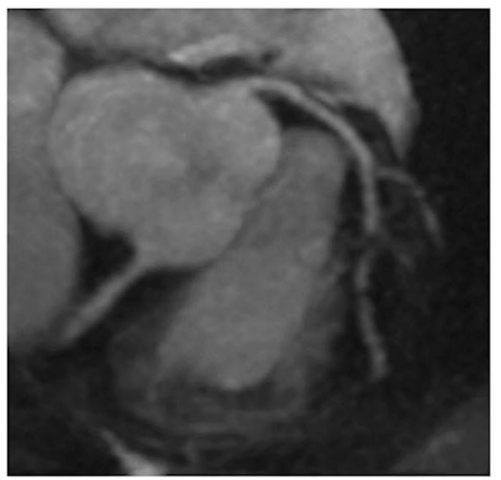

(c)

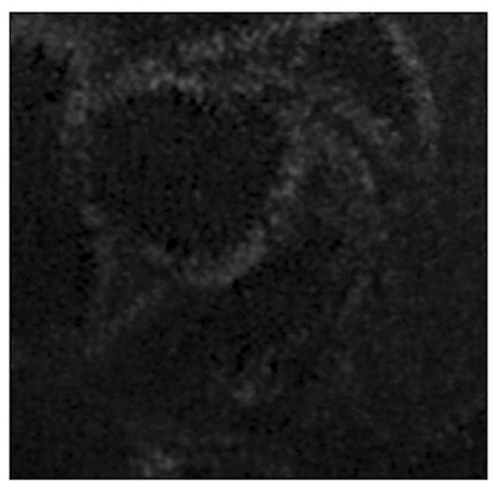

(f)

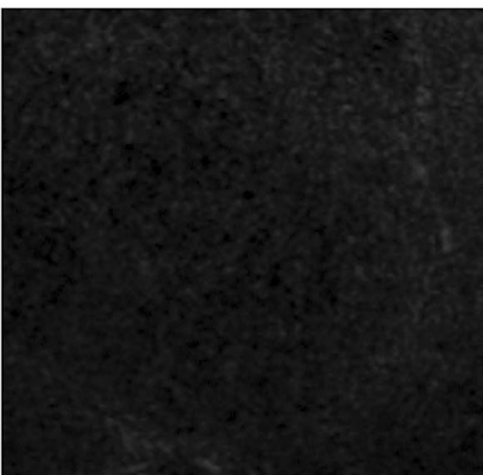

Fig. 7 Comparison of subtracted noises by conventional denoising and DLR on the same coronary MRA data set. a, d Same original coronary MRA images acquired with parallel imaging acceleration technique. b Coronary MRA image after conventional denoising. e Coronary MRA image after DLR. $\mathbf{c}$ The subtracted noise between a and $\mathbf{b}$. f The subtracted noise between $\mathbf{d}$ and $\mathbf{e}$. All the panels $\mathbf{a}-\mathbf{f}$ are in the same WL and WW. Subtraction images show that conventional denoising removes the edges from the original coronary MRA image (c), while DLR works on noise and retains the edge information (f). Consequently, the signal-to-noise ratio is higher in DLR processed image (e) than the conventional denoised image (b). The original image was acquired with a spoiled gradient echo sequence with ECG-

Learning a specific type of noise in advance such as in a trainable nonlinear reaction diffusion (TNRD) model [113] would restrict its performance to the specified forms of prior learning and accordingly limited in blind image denoising. To overcome this problem, feedforward denoising convolutional neural networks (DnCNNs) were proposed by Zhang et al., which are capable of handling Gaussian denoising with unknown noise levels [114]. Isogawa et al. proposed an adaptive approach by using soft shrinkage for the activation function of deep CNN resulting in a noise adaptive algorithm [115]. Furthermore, in one implementation [116], the application of $7 \times 7$ discrete cosine transform (DCT) convolution to extract higher frequency components followed by deep learning-based CNN using soft shrinkage for adaptive denoising successfully removed noise regardless of SNR gating, diaphragm navigator gating, and fat suppression with spectral attenuated inversion recovery. The MRI acquisition parameters were FOV $=380 \times 380 \mathrm{~mm}$, matrix $=392 \times 384$, slice thickness $=1.0 \mathrm{~mm}$, slice number $=152$, acceleration factor $=2.0 \times 2.0, \quad T R=5.3 \mathrm{~ms}$, $\mathrm{TE}=2.0 \mathrm{~ms}$, flip angle $=12$ degree, bandwidth $=279 \mathrm{~Hz} / \mathrm{pix}$, acquisition voxel size $=1.0 \times 1.0 \times 1.0 \mathrm{~mm}$, reconstructed voxel size $=0.5 \times 0.5 \times 0.5 \mathrm{~mm}$, navigator gating window $=4 \mathrm{~mm}$. For the conventional filtering, GA01 filter was used. For the DLR technique, see references $[116,140]$. DLR deep learning reconstruction, MRA magnetic resonance angiography, $W L$ window level, $W W$ window width, $G A$ gain algorithm

parameters such as contrast settings, matrix size, 2D and 3D, among other variables.

While still in its infancy, the use of deep learning strategies shows promise in denoising coronary MRA images, where fine anatomical images require good edge preservation and high SNR [19, 20]. Its flexibility with various noise levels and noise types is a great advantage when scanning patients with different body sizes. Its potential application to different frameworks may be valuable when combined with image acquisition acceleration techniques. However, care must be taken with regard to the application of deep learning reconstruction methods, since inappropriate denoising may cause artificial image manipulation leading to a loss of accuracy in image interpretation and reported clinical findings. Further validation is therefore necessary before adoption. 


\section{Opportunities for utilization from research-based modality to clinically utilized modality}

At present, there is no standardization of coronary MRA assessment methods. Currently available research-based methods are summarized in Table 2, and will be discussed in the following.

\section{Software development for the assessment of coronary MRA images}

While there are many multipurpose cardiovascular analysis packages, there are few dedicated non-contrast coronary MRA assessment tools commercially available or widely used. Coronary tree tracking and stenosis assessment remain a labor-intensive and time-consuming process. There are several specific reasons for this: (1) low SNR of the coronary lumen, (2) vulnerability of the coronary MRA images to artifacts that hamper autotracking of the vessels, and (3) rather low resolution of the image that prevents tracking of the smaller side branches. Attempts such as the "soap-bubble method" which assumed the coronary tree distribution on a relatively smooth 3D surface of a soap bubble to derive the final 2D maximum intensity projection image [117] or coronary MRA vessel centerline tracking and boundary segmentation based on geometric deformable models and optimized energy forces [118] have been previously reported. However, the application of these techniques in different clinical settings as well as their robustness remains untested.

\section{Coronary MRA stenosis assessment by signal intensity (SI) drop quantification}

Coronary MRA interpretation is usually performed visually, but its quantification is important for the generalization of the method. A previous study investigated the signal intensity (SI) profile across the coronary artery and reported an SI drop of $35 \%$ corresponding to significant stenosis by CAG (Fig. 8) [119]. Notably, this SI drop was not observed in chronic total obstruction cases [120]. One possible explanation is that the SI is affected not only by the stenosis severity, but also by the plaque characteristics.

\section{Plaque assessment}

Various sequences have been investigated for plaque assessment, though none of these techniques are currently viable clinically. T1-weighted magnetization-prepared rapid acquisition with gradient echo (MPRAGE) (Fig. 9) [121-123] and $\mathrm{T} 2 *[124,125]$ images describe iron accumulation in the vulnerable plaque. Noguchi et al. have reported that the presence of high-intensity plaque (HIP) on MPRAGE image was significantly associated with coronary events $(p<0.0001$, $\mathrm{HR}=3.15$ ) [122]. HIP detection prior to PCI was reported to be clinically relevant to avoid no-reflow phenomenon [123]. Ultrashort echo time (UTE) [126, 127] and susceptibility weighted imaging [128] are used to improve the visualization of calcified plaque. The distribution of iron and calcium is under research interest, since iron is suspected to accelerate the progression of atherosclerotic lesions while suppressing its calcification, and alternatively calcification could defend against atherosclerotic progression by excluding iron [129].

\section{Physiological assessment of the coronary arteries}

Physiological coronary function assessment by MRI uses phase-contrast (PC) imaging to quantify the blood flow through the coronary arteries. Sakuma et al. have reported in their canine study that the coronary blood flow (CBF) measured with the PC technique correlated well with flowmeter measurements [130]. Flow in the coronary sinus, which represents $96 \%$ of the total myocardial blood flow [131], has also been assessed [132, 133]. Lund et al. have reported

Table 2 Summary of research-based coronary MRA assessment methods

\begin{tabular}{ll}
\hline Target of the assessment & Methods \\
\hline 1. Stenosis severity & Signal intensity drop quantification $[119,120]$ \\
2. Plaque characteristics & MPRAGE $[122,123,141]$ and T2* $[124,125]$ images for the iron accumulation detection in \\
& vulnerable plaques \\
& Ultrashort TE (UTE) for fibrosis and calcification detection [126, 127] \\
& Susceptibility weighted imaging for calcification detection [128] \\
& Phase contrast-based coronary blood flow, coronary sinus flow, and coronary flow reserve \\
3. Physiological function & measurement [130, 132-137] \\
& Pressure gradient along the stenotic lesion [138] \\
& 4D flow [139]
\end{tabular}

MRA magnetic resonance angiography, MPRAGE magnetization-prepared rapid acquisition with gradient echo, UTE ultrashort echo time 

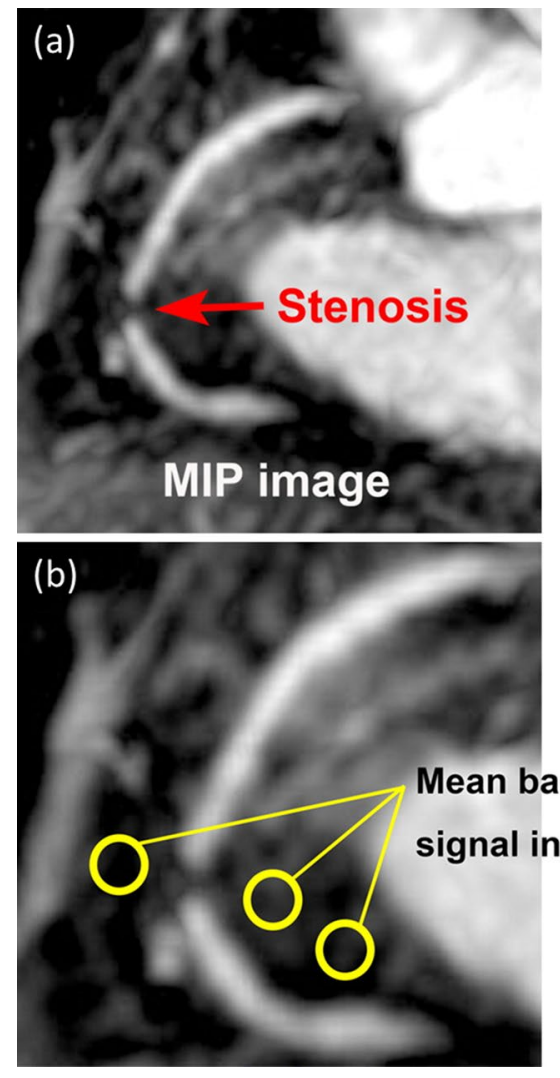

Fig. 8 QA of narrowing in the coronary artery on the basis of the signal intensity profile along the vessel. a MIP image of the major coronary vessel was generated from a three-dimensional coronary MRA. b Background signal intensity was measured by placing three ROIs (yellow circles) in pericardial fat on the image and averaging signal intensity values in three ROIs. $\mathbf{c}$ A stretched multiplanar reconstruction image was reconstructed along the artery, and signal intensity was determined by placing an elongated rectangular ROI with a width of 3 pixels along the vessel lumen (yellow elongated rectangular ROI). A luminal signal-intensity profile was generated after sub-

in a canine model that $\mathrm{CBF}$ measured in the left anterior descending (LAD) and left circumflex (LCX) showed excellent correlation with the flow of coronary sinus $(r=0.98$, $p<0.001$ ) [132]. Coronary flow reserve (CFR) which is the fractional $\mathrm{CBF}$ increase induced by stress agent is another target. Sakuma et al. have reported that the CFR measured in LAD in healthy subjects was significantly higher than that in patients with significant LAD stenosis [134]. Kato et al. have reported that in patients with suspected coronary artery disease, CFR assessed on the coronary sinus flow showed higher hazard ratio (HR) for the prediction of major adverse cardiac events than the presence of $>10 \%$ ischemia on stress perfusion cardiac magnetic resonance (HR: 14.16 vs 6.50 , respectively) [133]. These physiological measurements estimate the severity and extent of atherosclerotic burden, including the presence of multi-vessel disease or
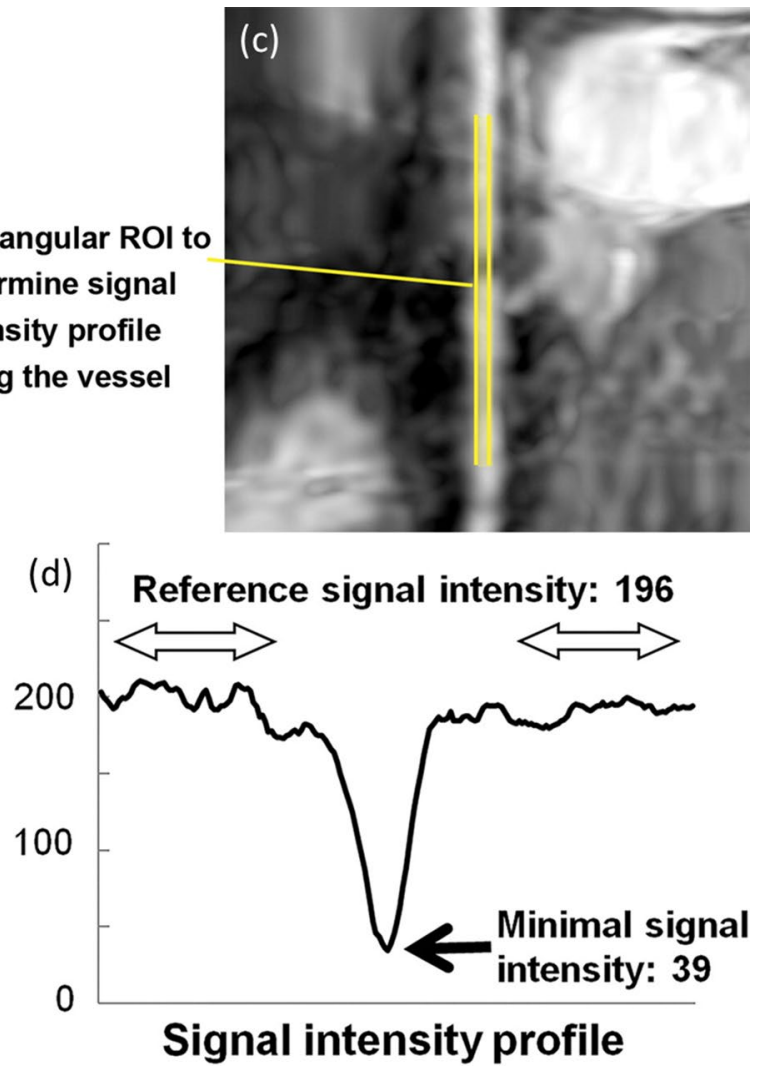

tracting the background signal intensity. $\mathbf{d}$ The percentage stenosis of the coronary artery was determined by measuring the minimal signal intensity at the stenotic lesion and the signal intensity at a reference location without stenosis. In this case, background signal intensity was 25 , reference signal intensity was 196 (221-25), minimal signal intensity was 39 (64-25), and percentage stenosis with QA of coronary MRA was $80.1 \%$ [1 - $(39 / 196) \times 100]$. $Q A$ quantitative analysis, $M I P$ maximum intensity projection, $M R A$ magnetic resonance angiography, ROI region of interest. (Reprinted with permission from Yonezawa et al. [119] Copyright @ 2013 by RSNA)

microvascular dysfunction $[135,136]$. The prognostic value of CFR [133, 135-137] is noted and it can be a good candidate for a "non-contrast one-stop-shop-test" to be combined with coronary MRA.

Meanwhile, another measurement of coronary flow, the functional flow ratio (FFR), is still under development. Direct assessment of the pressure gradient $(\Delta P)$ along the stenotic coronary artery with PC imaging was reported by Deng et al., who observed a significant increase in $\Delta P$ in suspected coronary stenosis lesions than in controls $(6.40 \pm 4.43 \mathrm{mmHg}$ vs. $0.70 \pm 0.57 \mathrm{mmHg}, p=0.025)$ [138]. Current technical problems related to this PC application are the partial volume effects at stenotic regions, possible impact from turbulence on the accuracy of PC-MRI velocity measurements, and the need to cope with cardiac and respiratory motion [138]. 4D flow is an advanced promising technique 

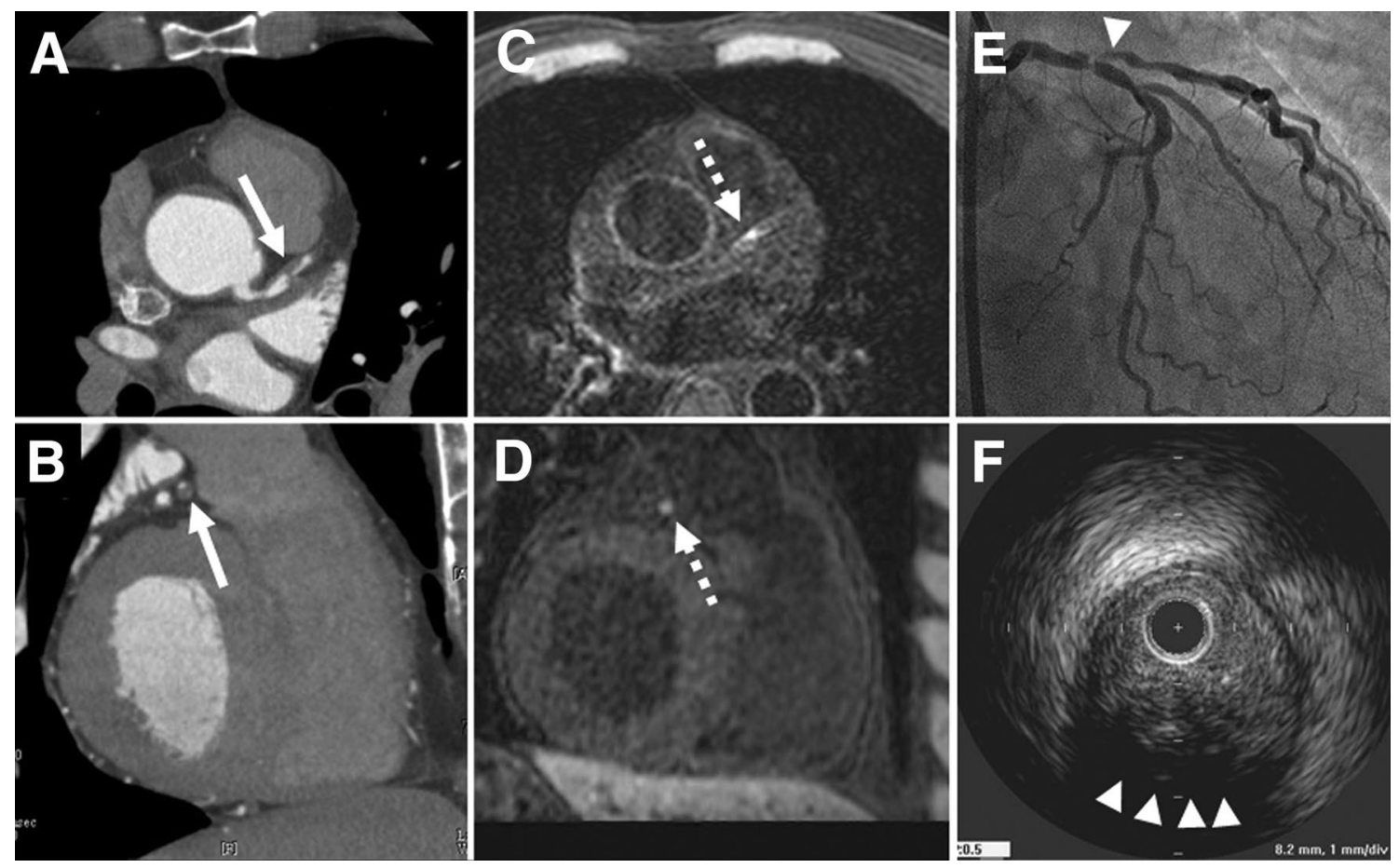

Fig. 9 Representative case of HIP in the proximal LAD is presented. Coronary CTA (a horizontal, b sagittal) demonstrates the low-density positive remodeling plaque ( -32 Hounsfield units, remodeling index: 1.27) (arrow) with severe coronary stenosis in the proximal LAD. On the corresponding CMR (c horizontal, d sagittal), this low-density plaque was visualized as a "hyperintense spot" (dashed arrow). On the coronary angiography, severe coronary stenosis was observed (e) (arrowhead), and on IVUS examination (f), positive remodeling

of PC with flow encoding in all three dimensions of space, plus time along the cardiac cycle. The current typical spatial resolution of $4 \mathrm{D}$ flow is $1.5 \times 1.5 \times 1.5$ to $3 \times 3 \times 3 \mathrm{~mm}^{3}$ [139], which is not enough for coronary artery imaging. Further developments with higher resolution are expected.

\section{Conclusions}

Non-contrast coronary MRA is a non-invasive, non-ionizing radiation modality that is particularly unique, as it does not require contrast use to enhance intra-luminal blood flow. These characteristics have great potential for routine clinical applications. We reviewed the current clinical use and the in-progress technical developments that could significantly impact coronary MRA prospectively. The central thesis is that the combination of PI and CS is expected to maintain high spatial resolution while reducing the total time of acquisition, and application of DLR is promising for effective denoizing to improve SNR and CNR. Research-based plaque (remodeling index: 1.29) with ultrasound attenuation (arrowheads) was observed in the proximal LAD, corresponding to the plaque observed by both coronary CTA and CMR. HIP hyperintense plaque, $L A D$ left anterior descending artery, CTA computer tomography angiography, $C M R$ cardiac magnetic resonance, IVUS intravascular ultrasound. (Reprinted with permission from Kawasaki et al. [121] Copyright (C) 2009 by the American College of Cardiology Foundation)

coronary MRA assessment methods of stenosis severity, physiological function, and plaque characteristics are being developed to transform coronary MRA into a robust noninvasive imaging modality to be used routinely for clinical decision making in cardiovascular medicine.

Acknowledgements This study was supported by Canon Medical Systems Corporation, grant \# 16-00632. YK, LK, JS, and SC are Canon Medical Systems employees in research and development roles. This work represents ongoing R\&D between our group at Johns Hopkins Hospital and Canon Medical Systems. We have been particularly careful at eliminating any perception of bias.

Author contributions YK performed the literature search, data analysis and interpretation, drafting, and critical revision of the work. BAV, SC, and JACL performed the study conception and the critical revision. YK and LK helped in the acquisition of the data, analysis, interpretation of the data, and the critical revision. JS and KK helped in critical revision. All authors contributed to the idea for the article. All authors read and approved the final manuscript.

Funding This study was funded by Canon Medical Systems Corporation, Grant \# 16-00632. 


\section{Compliance with ethical standards}

Conflict of interest Author Joao A.C. Lima has received research grants from Canon Medical Systems Corporation. Yoshimori Kassai, Larry Kasuboski, Joanne Schijf, and Shelton Caruthers are Canon Medical Systems employees in research and development roles. This work represents ongoing R\&D between our group at Johns Hopkins Hospital and Canon Medical Systems. We have been particularly careful at eliminating any perception of bias. The remaining authors declare that he/she has no conflict of interest.

Ethical approval All procedures performed in studies involving human participants were in accordance with the ethical standards of the institutional and/or national research committee and with the 1964 Helsinki Declaration and its later amendments or comparable ethical standards.

Informed consent Informed consent was obtained from all individual participants included in the study.

Open Access This article is licensed under a Creative Commons Attribution 4.0 International License, which permits use, sharing, adaptation, distribution and reproduction in any medium or format, as long as you give appropriate credit to the original author(s) and the source, provide a link to the Creative Commons licence, and indicate if changes were made. The images or other third party material in this article are included in the article's Creative Commons licence, unless indicated otherwise in a credit line to the material. If material is not included in the article's Creative Commons licence and your intended use is not permitted by statutory regulation or exceeds the permitted use, you will need to obtain permission directly from the copyright holder. To view a copy of this licence, visit http://creativecommons.org/licenses/by/4.0/.

\section{References}

1. Manning WJ, Li W, Edelman RR (1993) A preliminary report comparing magnetic resonance coronary angiography with conventional angiography. N Engl J Med 328:828-832

2. Dewey M (2011) Coronary CT versus MR angiography: pro CT - the role of CT angiography. Radiology 258:329-339

3. Di Leo G, Fisci E, Secchi F, Alì M, Ambrogi F, Sconfienza LM, Sardanelli F (2016) Diagnostic accuracy of magnetic resonance angiography for detection of coronary artery disease: a systematic review and meta-analysis. Eur Radiol 26:3706-3718

4. Kelle S, Hays AG, Hirsch GA, Gerstenblith G, Miller JM, Steinberg AM, Schär M, Texter JH, Wellnhofer E, Weiss RG, Stuber M (2011) Coronary artery distensibility assessed by 3.0 Tesla coronary magnetic resonance imaging in subjects with and without coronary artery disease. Am J Cardiol 108:491-497

5. Nguyen PK, Meyer C, Engvall J, Yang P, McConnell MV (2008) Noninvasive assessment of coronary vasodilation using cardiovascular magnetic resonance in patients at high risk for coronary artery disease. J Cardiovasc Magn Reson 10:28

6. Hays AG, Stuber M, Hirsch GA, Yu J, Schär M, Weiss RG, Gerstenblith G, Kelle S (2013) Non-invasive detection of coronary endothelial response to sequential handgrip exercise in coronary artery disease patients and healthy adults. PLoS ONE 8:1-8

7. Botnar RM, Stuber M, Kissinger KV, Kim WY, Spuentrup E, Manning WJ (2000) Noninvasive coronary vessel wall and plaque imaging with magnetic resonance imaging. Circulation 102:2582-2587
8. Yeon SB, Sabir A, Clouse M, Martinezclark PO, Peters DC, Hauser TH, Gibson CM, Nezafat R, Maintz D, Manning WJ, Botnar RM (2007) Delayed-enhancement cardiovascular magnetic resonance coronary artery wall imaging: comparison with multislice computed tomography and quantitative coronary angiography. J Am Coll Cardiol 50:441-447

9. Sakuma H, Ichikawa Y, Suzawa N, Hirano T, Makino K, Koyama N, Van Cauteren M, Takeda K (2005) Assessment of coronary arteries with total study time of less than 30 minutes by using whole-heart coronary MR angiography. Radiology 237:316-321

10. Hamdan A, Asbach P, Wellnhofer E, Klein C, Gebker R, Kelle S, Kilian H, Huppertz A, Fleck E (2011) A prospective study for comparison of MR and CT imaging for detection of coronary artery stenosis. JACC Cardiovasc Imaging 4:50-61

11. Kim WY, Danias PG, Stuber M, Flamm SD, Plein S, Nagel E, Langerak SE, Weber OM, Pedersen EM, Schmidt M, Botnar RM, Manning WJ (2001) Coronary magnetic resonance angiography for the detection of coronary stenoses. N Engl J Med 345:1863-1869

12. Kato S, Kitagawa K, Ishida N, Ishida M, Nagata M, Ichikawa Y, Katahira K, Matsumoto Y, Seo K, Ochiai R, Kobayashi Y, Sakuma H (2010) Assessment of coronary artery disease using magnetic resonance coronary angiography: a national multicenter trial. J Am Coll Cardiol 56:983-991

13. Bluemke DA, Achenbach S, Budoff M, Gerber TC, Gersh B, Hillis LD, Hundley WG, Manning WJ, Printz BF, Stuber M, Woodard PK (2008) Noninvasive coronary artery imaging: magnetic resonance angiography and multidetector computed tomography angiography: a scientific statement from the american heart association committee on cardiovascular imaging and intervention of the council on cardio. Circulation 118:586-606

14. Hundley WG, Bluemke DA, Finn JP, Flamm SD, Fogel MA, Friedrich MG, Ho VB, Jerosch-Herold M, Kramer CM, Manning WJ, Patel M, Pohost GM, Stillman AE, White RD, Woodard PK (2010) ACCF/ACR/AHA/NASCI/SCMR 2010 expert consensus document on cardiovascular magnetic resonance. A report of the American College of Cardiology Foundation Task Force on Expert Consensus Documents. J Am Coll Cardiol 55:2614-2662

15. Nakamura M, Kido T, Kido T, Watanabe K, Schmidt M, Forman C, Mochizuki T (2018) Non-contrast compressed sensing whole-heart coronary magnetic resonance angiography at 3T: a comparison with conventional imaging. Eur J Radiol 104:43-48

16. Akçakaya M, Basha TA, Chan RH, Manning WJ, Nezafat R (2014) Accelerated isotropic sub-millimeter whole-heart coronary MRI: compressed sensing versus parallel imaging. Magn Reson Med 71:815-822

17. Pang J, Sharif B, Fan Z, Bi X, Arsanjani R, Berman DS, Li D (2014) ECG and navigator-free four-dimensional whole-heart coronary MRA for simultaneous visualization of cardiac anatomy and function. Magn Reson Med 72:1208-1217

18. Feng L, Coppo S, Piccini D, Yerly J, Lim RP, Masci PG, Stuber M, Sodickson DK, Otazo R (2018) 5D whole-heart sparse MRI. Magn Reson Med 79:826-838

19. Kato Y, Ambale-venkatesh B, Kassai Y, Pitts J, Kasuboski L, Ortman J, Caruthers S, Lima JAC (2019) Application of deep learning reconstruction for denoising of compressed sensing noncontrast coronary MRA images to achieve improved diagnostic confidence. ISMRM 2019 Abstr

20. Takahashi S, Machida H, Kariyasu T, Niitsu R, Miyazaki I, Yoshioka T, Fukushima K, Yuda S, Shimizu Y, Yonaha T, Nakanishi A, Kusahara H, Matsuoka Y, Kitamura M, Yamamoto T, Yokoyama K (2019) Improved vessel delineation in whole-heart coronary MRA with sub-millimeter isotropic resolution using deep learning reconstruction compared with routine whole-heart coronary MRA. ISMRM 2019 Abstr 
21. Roth GA, Abate D, Abate KH, Abay SM, Abbafati C, Abbasi N, Abbastabar H, Abd-Allah F, Abdela J, Abdelalim A, Abdollahpour I, Abdulkader RS, Abebe HT, Abebe M, Abebe Z, Abejie AN, Abera SF, Abil OZ, Abraha HN, Abrham AR, Abu-Raddad LJ, Accrombessi MMK, Acharya D, Adamu AA, Adebayo OM, Adedoyin RA, Adekanmbi V, Adetokunboh OO, Adhena BM, Adib MG, Admasie A, Afshin A, Agarwal G, Agesa KM, Agrawal A, Agrawal S, Ahmadi A, Ahmadi M, Ahmed MB, Ahmed S, Aichour AN, Aichour I, Aichour MTE, Akbari ME, Akinyemi RO, Akseer N, Al-Aly Z, Al-Eyadhy A, Al-Raddadi RM, Alahdab F, Alam K, Alam T, Alebel A, Alene KA, Alijanzadeh M, Alizadeh-Navaei R, Aljunid SM, Alkerwi A, Alla F, Allebeck P, Alonso J, Altirkawi K, Alvis-Guzman N, Amare AT, Aminde LN, Amini E, Ammar W, Amoako YA, Anber NH, Andrei CL, Androudi S, Animut MD, Anjomshoa M, Ansari H, Ansha MG, Antonio CAT, Anwari P, Aremu O, Arnlov J, Arora A, Arora M, Artaman A, Aryal KK, Asayesh H, Asfaw ET, Ataro Z, Atique S, Atre SR, Ausloos M, Avokpaho EFGA, Awasthi A, Ayala Quintanilla BP, Ayele Y, Ayer R, Azzopardi PS, Babazadeh A, Bacha U, Badali H, Badawi A, Bali AG, Ballesteros KE, Banach M, Banerjee K, Bannick MS, Banoub JAM, Barboza MA, Barker-Collo SL, Barnighausen TW, Barquera S, Barrero LH, Bassat Q, Basu S, Baune BT, Baynes HW, Bazargan-Hejazi S, Bedi N, Beghi E, Behzadifar M, Behzadifar M, Bejot Y, Bekele BB, Belachew AB, Belay E, Belay YA, Bell ML, Bello AK, Bennett DA, Bensenor IM, Berman AE, Bernabe E, Bernstein RS, Bertolacci GJ, Beuran M, Beyranvand T, Bhalla A, Bhattarai S, Bhaumik S, Bhutta ZA, Biadgo B, Biehl MH, Bijani A, Bikbov B, Bilano V, Bililign N, Bin Sayeed MS, Bisanzio D, Biswas T, Blacker BF, Basara BB, Borschmann R, Bosetti C, Bozorgmehr K, Brady OJ, Brant LC, Brayne C, Brazinova A, Breitborde NJK, Brenner H, Briant PS, Britton G, Brugha T, Busse R, Butt ZA, Callender CSKH, Campos-Nonato IR, Campuzano Rincon JC, Cano J, Car M, Cardenas R, Carreras G, Carrero JJ, Carter A, Carvalho F, Castaneda-Orjuela CA, Castillo Rivas J, Castle CD, Castro C, Castro F, Catala-Lopez F, Cerin E, Chaiah Y, Chang JC, Charlson FJ, Chaturvedi P, Chiang PPC, Chimed-Ochir O, Chisumpa VH, Chitheer A, Chowdhury R, Christensen H, Christopher DJ, Chung SC, Cicuttini FM, Ciobanu LG, Cirillo M, Cohen AJ, Cooper LT, Cortesi PA, Cortinovis M, Cousin E, Cowie BC, Criqui MH, Cromwell EA, Crowe CS, Crump JA, Cunningham M, Daba AK, Dadi AF, Dandona L, Dandona R, Dang AK, Dargan PI, Daryani A, Das SK, Gupta R Das, Neves J Das, Dasa TT, Dash AP, Davis AC, Davis Weaver N, Davitoiu DV, Davletov K, De La Hoz FP, De Neve JW, Degefa MG, Degenhardt L, Degfie TT, Deiparine S, Demoz GT, Demtsu BB, Denova-Gutierrez E, Deribe K, Dervenis N, Des Jarlais DC, Dessie GA, Dey S, Dharmaratne SD, Dicker D, Dinberu MT, Ding EL, Dirac MA, Djalalinia S, Dokova K, Doku DT, Donnelly CA, Dorsey ER, Doshi PP, Douwes-Schultz D, Doyle KE, Driscoll TR, Dubey M, Dubljanin E, Duken EE, Duncan BB, Duraes AR, Ebrahimi H, Ebrahimpour S, Edessa D, Edvardsson D, Eggen AE, El Bcheraoui C, El Sayed Zaki M, El-Khatib Z, Elkout H, Ellingsen CL, Endres M, Endries AY, Er B, Erskine HE, Eshrati B, Eskandarieh S, Esmaeili R, Esteghamati A, Fakhar M, Fakhim H, Faramarzi M, Fareed M, Farhadi F, Farinha CSE, Faro A, Farvid MS, Farzadfar F, Farzaei MH, Feigin VL, Feigl AB, Fentahun N, Fereshtehnejad SM, Fernandes E, Fernandes JC, Ferrari AJ, Feyissa GT, Filip I, Finegold S, Fischer F, Fitzmaurice C, Foigt NA, Foreman KJ, Fornari C, Frank TD, Fukumoto T, Fuller JE, Fullman N, Furst T, Furtado JM, Futran ND, Gallus S, Garcia-Basteiro AL, Garcia-Gordillo MA, Gardner WM, Gebre AK, Gebrehiwot TT, Gebremedhin AT, Gebremichael B, Gebremichael TG, Gelano TF, Geleijnse JM, Genova-Maleras R, Geramo YCD, Gething PW, Gezae KE, Ghadami MR, Ghadimi R, Ghasemi Falavarjani K,
Ghasemi-Kasman M, Ghimire M, Gibney KB, Gill PS, Gill TK, Gillum RF, Ginawi IA, Giroud M, Giussani G, Goenka S, Goldberg EM, Goli S, Gomez-Dantes H, Gona PN, Gopalani SV, Gorman TM, Goto A, Goulart AC, Gnedovskaya E V., Grada A, Grosso G, Gugnani HC, Guimaraes ALS, Guo Y, Gupta PC, Gupta R, Gupta R, Gupta T, Gutierrez RA, Gyawali B, Haagsma JA, Hafezi-Nejad N, Hagos TB, Hailegiyorgis TT, Hailu GB, Haj-Mirzaian A, Haj-Mirzaian A, Hamadeh RR, Hamidi S, Handal AJ, Hankey GJ, Harb HL, Harikrishnan S, Haro JM, Hasan M, Hassankhani H, Hassen HY, Havmoeller R, Hay RJ, Hay SI, He Y, Hedayatizadeh-Omran A, Hegazy MI, Heibati B, Heidari M, Hendrie D, Henok A, Henry NJ, Herteliu C, Heydarpour F, Heydarpour P, Heydarpour S, Hibstu DT, Hoek HW, Hole MK, Homaie Rad E, Hoogar P, Hosgood HD, Hosseini SM, Hosseinzadeh M, Hostiuc M, Hostiuc S, Hotez PJ, Hoy DG, Hsiao T, Hu G, Huang JJ, Husseini A, Hussen MM, Hutfless S, Idrisov B, Ilesanmi OS, Iqbal U, Irvani SSN, Irvine CMS, Islam N, Islam SMS, Islami F, Jacobsen KH, Jahangiry L, Jahanmehr N, Jain SK, Jakovljevic M, Jalu MT, James SL, Javanbakht M, Jayatilleke AU, Jeemon P, Jenkins KJ, Jha RP, Jha V, Johnson CO, Johnson SC, Jonas JB, Joshi A, Jozwiak JJ, Jungari SB, Jurisson M, Kabir Z, Kadel R, Kahsay A, Kalani R, Karami M, Karami Matin B, Karch A, Karema C, Karimi-Sari H, Kasaeian A, Kassa DH, Kassa GM, Kassa TD, Kassebaum NJ, Katikireddi SV, Kaul A, Kazemi Z, Kazemi Karyani A, Kazi DS, Kefale AT, Keiyoro PN, Kemp GR, Kengne AP, Keren A, Kesavachandran CN, Khader YS, Khafaei B, Khafaie MA, Khajavi A, Khalid N, Khalil IA, Khan EA, Khan MS, Khan MA, Khang YH, Khater MM, Khoja AT, Khosravi A, Khosravi MH, Khubchandani J, Kiadaliri AA, Kibret GD, Kidanemariam ZT, Kiirithio DN, Kim D, Kim YE, Kim YJ, Kimokoti RW, Kinfu Y, Kisa A, Kissimova-Skarbek K, Kivimaki M, Knudsen AKS, Kocarnik JM, Kochhar S, Kokubo Y, Kolola T, Kopec JA, Koul PA, Koyanagi A, Kravchenko MA, Krishan K, Kuate Defo B, Kucuk Bicer B, Kumar GA, Kumar M, Kumar P, Kutz MJ, Kuzin I, Kyu HH, Lad DP, Lad SD, Lafranconi A, Lal DK, Lalloo R, Lallukka T, Lam JO, Lami FH, Lansingh VC, Lansky S, Larson HJ, Latifi A, Lau KMM, Lazarus J V., Lebedev G, Lee PH, Leigh J, Leili M, Leshargie CT, Li S, Li Y, Liang J, Lim LL, Lim SS, Limenih MA, Linn S, Liu S, Liu Y, Lodha R, Lonsdale C, Lopez AD, Lorkowski S, Lotufo PA, Lozano R, Lunevicius R, Ma S, Macarayan ERK, Mackay MT, MacLachlan JH, Maddison ER, Madotto F, Magdy Abd El Razek H, Magdy Abd El Razek M, Maghavani DP, Majdan M, Majdzadeh R, Majeed A, Malekzadeh R, Malta DC, Manda AL, Mandarano-Filho LG, Manguerra H, Mansournia MA, Mapoma CC, Marami D, Maravilla JC, Marcenes W, Marczak L, Marks A, Marks GB, Martinez G, MartinsMelo FR, Martopullo I, Marz W, Marzan MB, Masci JR, Massenburg BB, Mathur MR, Mathur P, Matzopoulos R, Maulik PK, Mazidi M, McAlinden C, McGrath JJ, McKee M, McMahon BJ, Mehata S, Mehndiratta MM, Mehrotra R, Mehta KM, Mehta V, Mekonnen TC, Melese A, Melku M, Memiah PTN, Memish ZA, Mendoza W, Mengistu DT, Mengistu G, Mensah GA, Mereta ST, Meretoja A, Meretoja TJ, Mestrovic T, Mezgebe HB, Miazgowski B, Miazgowski T, Millear AI, Miller TR, MillerPetrie MK, Mini GK, Mirabi P, Mirarefin M, Mirica A, Mirrakhimov EM, Misganaw AT, Mitiku H, Moazen B, Mohammad KA, Mohammadi M, Mohammadifard N, Mohammed MA, Mohammed S, Mohan V, Mokdad AH, Molokhia M, Monasta L, Moradi G, Moradi-Lakeh M, Moradinazar M, Moraga P, Morawska L, Velasquez IM, Morgado-Da-Costa J, Morrison SD, Moschos MM, Mouodi S, Mousavi SM, Muchie KF, Mueller UO, Mukhopadhyay S, Muller K, Mumford JE, Musa J, Musa KI, Mustafa G, Muthupandian S, Nachega JB, Nagel G, Naheed A, Nahvijou A, Naik G, Nair S, Najafi F, Naldi L, Nam HS, Nangia V, Nansseu JR, Nascimento BR, Natarajan G, Neamati 
N, Negoi I, Negoi RI, Neupane S, Newton CRJ, Ngalesoni FN, Ngunjiri JW, Nguyen AQ, Nguyen G, Nguyen HT, Nguyen HT, Nguyen LH, Nguyen M, Nguyen TH, Nichols E, Ningrum DNA, Nirayo YL, Nixon MR, Nolutshungu N, Nomura S, Norheim OF, Noroozi M, Norrving B, Noubiap JJ, Nouri HR, Shiadeh MN, Nowroozi MR, Nyasulu PS, Odell CM, Ofori-Asenso R, Ogbo FA, Oh IH, Oladimeji O, Olagunju AT, Olivares PR, Olsen HE, Olusanya BO, Olusanya JO, Ong KL, Ong SKS, Oren E, Orpana HM, Ortiz A, Ortiz JR, Otstavnov SS, Overland S, Owolabi MO, Ozdemir R, Mahesh PA, Pacella R, Pakhale S, Pakhare AP, Pakpour AH, Pana A, Panda-Jonas S, Pandian JD, Parisi A, Park EK, Parry CDH, Parsian H, Patel S, Pati S, Patton GC, Paturi VR, Paulson KR, Pereira A, Pereira DM, Perico N, Pesudovs K, Petzold M, Phillips MR, Piel FB, Pigott DM, Pillay JD, Pirsaheb M, Pishgar F, Polinder S, Postma MJ, Pourshams A, Poustchi H, Pujar A, Prakash S, Prasad N, Purcell CA, Qorbani M, Quintana H, Quistberg DA, Rade KW, Anwar Rafay AR, Rahim F, Rahimi K, Rahimi-Movaghar A, Rahman M, Rahman MHU, Rahman MA, Rai RK, Rajsic S, Ram U, Ranabhat CL, Ranjan P, Rao PC, Rawaf DL, Rawaf S, Razo-Garcia C, Reddy KS, Reiner RC, Reitsma MB, Remuzzi G, Renzaho AMN, Resnikoff S, Rezaei S, Rezaeian S, Rezai MS, Riahi SM, Ribeiro ALP, Rios-Blancas MJ, Roba KT, Roberts NLS, Robinson SR, Roever L, Ronfani L, Roshandel G, Rostami A, Rothenbacher D, Roy A, Rubagotti E, Sachdev PS, Saddik B, Sadeghi E, Safari H, Safdarian M, Safi S, Safiri S, Sagar R, Sahebkar A, Sahraian MA, Salam N, Salama JS, Salamati P, De Freitas Saldanha R, Saleem Z, Salimi Y, Salvi SS, Salz I, Sambala EZ, Samy AM, Sanabria J, Dolores SanchezNino M, Santomauro DF, Santos IS, Santos JV, Santric Milicevic MM, Jose BPS, Sarker AR, Sarmiento-Suarez R, Sarrafzadegan N, Sartorius B, Sarvi S, Sathian B, Satpathy M, Sawant AR, Sawhney M, Saxena S, Sayyah M, Schaeffner E, Schmidt MI, Schneider IJC, Schottker B, Schutte AE, Schwebel DC, Schwendicke F, Scott JG, Sekerija M, Sepanlou SG, Servan-Mori E, Seyedmousavi S, Shabaninejad H, Shackelford KA, Shafieesabet A, Shahbazi M, Shaheen AA, Shaikh MA, Shams-Beyranvand M, Shamsi M, Shamsizadeh M, Sharafi K, Sharif M, SharifAlhoseini M, Sharma R, She J, Sheikh A, Shi P, Shiferaw MS, Shigematsu M, Shiri R, Shirkoohi R, Shiue I, Shokraneh F, Shrime MG, Si S, Siabani S, Siddiqi TJ, Sigfusdottir ID, Sigurvinsdottir R, Silberberg DH, Santos Silva DA, Silva JP, Da Silva NT, Silveira DGA, Singh JA, Singh NP, Singh PK, Singh V, Sinha DN, Sliwa K, Smith M, Sobaih BH, Sobhani S, Sobngwi E, Soneji SS, Soofi M, Sorensen RJD, Soriano JB, Soyiri IN, Sposato LA, Sreeramareddy CT, SrinivasanV, Stanaway JD, Starodubov VI, Stathopoulou V, Stein DJ, Steiner C, Stewart LG, Stokes MA, Subart ML, Sudaryanto A, Sufiyan MB, Sur PJ, Sutradhar I, Sykes BL, Sylaja PN, Sylte DO, Szoeke CEI, Tabares-Seisdedos R, Tabuchi T, Tadakamadla SK, Takahashi K, Tandon N, Tassew SG, Taveira N, Tehrani-Banihashemi A, Tekalign TG, Tekle MG, Temsah MH, Temsah O, Terkawi AS, Teshale MY, Tessema B, Tessema GA, Thankappan KR, Thirunavukkarasu S, Thomas N, Thrift AG, Thurston GD, Tilahun B, To QG, Tobe-Gai R, Tonelli M, Topor-Madry R, Torre AE, Tortajada-Girbes M, Touvier M, Tovani-Palone MR, Tran BX, Tran KB, Tripathi S, Troeger CE, Truelsen TC, Truong NT, Tsadik AG, Tsoi D, Tudor Car L, Murat Tuzcu E, Tyrovolas S, Ukwaja KN, Ullah I, Undurraga EA, Updike RL, Usman MS, Uthman OA, Uzun SB, Vaduganathan M, Vaezi A, Vaidya G, Valdez PR, Varavikova E, Vasankari TJ, Venketasubramanian N, Villafaina S, Violante FS, Vladimirov SK, Vlassov V, Vollset SE, Vos T, Wagner GR, Wagnew FS, Waheed Y, Wallin MT, Walson JL, Wang Y, Wang YP, Wassie MM, Weiderpass E, Weintraub RG, Weldegebreal F, Weldegwergs KG, Werdecker A, Werkneh AA, West TE, Westerman R, Whiteford HA, Widecka J, Wilner LB, Wilson S, Winkler AS, Wiysonge CS, Wolfe CDA, Wu S,
Wu YC, Wyper GMA, Xavier D, Xu G, Yadgir S, Yadollahpour A, Yahyazadeh Jabbari SH, Yakob B, Yan LL, Yano Y, Yaseri M, Yasin YJ, Yentur GK, Yeshaneh A, Yimer EM, Yip P, Yirsaw BD, Yisma E, Yonemoto N, Yonga G, Yoon SJ, Yotebieng M, Younis MZ, Yousefifard M, Yu C, Zadnik V, Zaidi Z, Zaman S Bin, Zamani M, Zare Z, Zeleke AJ, Zenebe ZM, Zhang AL, Zhang K, Zhou M, Zodpey S, Zuhlke LJ, Naghavi M, Murray CJL (2018) Global, regional, and national age-sex-specific mortality for 282 causes of death in 195 countries and territories, 1980-2017: a systematic analysis for the Global Burden of Disease Study 2017. Lancet 392:1736-1788

22. Patel MR, Dai D, Hernandez AF, Douglas PS, Messenger J, Garratt KN, Maddox TM, Peterson ED, Roe MT (2014) Prevalence and predictors of nonobstructive coronary artery disease identified with coronary angiography in contemporary clinical practice. Am Heart J 167:846-852.e2

23. Bradley SM, Maddox TM, Stanislawski MA, O'Donnell CI, Grunwald GK, Tsai TT, Ho PM, Peterson ED, Rumsfeld JS (2014) Normal coronary rates for elective angiography in the veterans affairs healthcare system: Insights from the VA CART program (Veterans Affairs Clinical Assessment Reporting and Tracking). J Am Coll Cardiol 63:417-426

24. Douglas PS, Patel MR, Bailey SR, Dai D, Kaltenbach L, Brindis RG, Messenger J, Peterson ED (2011) Hospital variability in the rate of finding obstructive coronary artery disease at elective, diagnostic coronary angiography. J Am Coll Cardiol 58:801-809

25. Tavakol M, Ashraf S, Brener SJ (2011) Risks and complications of coronary angiography: a comprehensive review. Glob J Health Sci 4:65-93

26. Zwadlo C, Meyer GP, Schieffer B, Westhoff-Bleck M (2012) Anomalous intramural course of coronary arteries in congenital heart disease-three case reports and review of the literature. Congenit Heart Dis 7:139-144

27. Albrecht MH, Varga-Szemes A, Schoepf UJ, Nance JW, De Cecco CN, De Santis D, Tesche C, Eid MH, Penmetsa M, Lesslie VW, Piccini D, Goeller M, Wichmann JL, Vogl TJ, Chowdhury SM, Nutting A, Hlavacek AM (2019) Diagnostic accuracy of noncontrast self-navigated free-breathing MR angiography versus CT angiography: a prospective study in pediatric patients with suspected anomalous coronary arteries. Acad Radiol 26:1309-1317

28. Walsh R, Nielsen JC, Ko HH, Sanz J, Srivastava S, Parness IA, Lytrivi ID (2011) Imaging of congenital coronary artery anomalies. Pediatr Radiol 41:1526-1535

29. Goo HW (2015) Coronary artery imaging in children. Korean J Radiol 16:239-250

30. Mavrogeni S, Papadopoulos G, Douskou M, Kaklis S, Seimenis I, Baras P, Nikolaidou P, Bakoula C, Karanasios E, Manginas A, Cokkinos DV (2004) Magnetic resonance angiography is equivalent to X-Ray coronary angiography for the evaluation of coronary arteries in kawasaki disease. J Am Coll Cardiol 43:649-652

31. Greil GF, Stuber M, Botnar RM, Kissinger KV, Geva T, Newburger JW, Manning WJ, Powell AJ (2002) Coronary magnetic resonance angiography in adolescents and young adults with Kawasaki disease. Circulation 105:908-911

32. JCS Joint Working Group (2014) Guidelines for diagnosis and management of cardiovascular sequelae in Kawasaki disease (JCS 2013). Digest version Circ J 78:2521-2562

33. Baumgartner H, Bonhoeffer P, De Groot NMS, de Haan F, Deanfield JE, Galie N, Gatzoulis MA, Gohlke-Baerwolf C, Kaemmerer H, Kilner P, Meijboom F, Mulder BJM, Oechslin E, Oliver JM, Serraf A, Szatmari A, Thaulow E, Vouhe PR, Walma E, Task Force on the Management of Grown-up Congenital Heart Disease of the European Society of Cardiology (ESC), Association for European Paediatric Cardiology (AEPC), ESC Committee for Practice Guidelines (CPG) (2010) ESC Guidelines for the 
management of grown-up congenital heart disease (new version 2010). Eur Heart J 31:2915-2957

34. Molen AJ Van Der, Reimer P, Dekkers IA, Bongartz G, Bellin M (2018) Post-contrast acute kidney injury-Part 1 : Definition, clinical features, incidence, role of contrast medium and risk factors. Am Coll Radiol 2845-2855

35. van der Molen AJ, Reimer P, Dekkers IA, Bongartz G, Bellin M-F, Bertolotto M, Clement O, Heinz-Peer G, Stacul F, Webb JAWW, Thomsen HS (2018) Post-contrast acute kidney injury. Part 2: risk stratification, role of hydration and other prophylactic measures, patients taking metformin and chronic dialysis patients: recommendations for updated ESUR Contrast Medium Safety Committee guidelines. Eur Radiol 28:2856-2869

36. Thomsen HS, Morcos SK, Almén T, Bellin MF, Bertolotto M, Bongartz G, Clement O, Leander P, Heinz-Peer G, Reimer P, Stacul F, Van Der Molen A, Webb JA (2013) Nephrogenic systemic fibrosis and gadolinium-based contrast media: updated ESUR Contrast Medium Safety Committee guidelines. Eur Radiol 23:307-318

37. Liu X, Zhao X, Huang J, Francois CJ, Tuite D, Bi X, Li D, Carr JC (2007) Comparison of 3D free-breathing coronary MR angiography and 64-MDCT angiography for detection of coronary stenosis in patients with high calcium scores. Am J Roentgenol 189:1326-1332

38. Kanda T, Ishii K, Kawaguchi H, Kitajima K, Takenaka D (2014) High signal intensity in the dentate nucleus and globus pallidus on unenhanced T1-weighted MR images: relationship with increasing cumulative dose of a gadolinium-based contrast material. Radiology 270:834-841

39. Kanda T, Fukusato T, Matsuda M, Toyoda K, Oba H, Kotoku J, Haruyama T, Kitajima K, Furui S (2015) Gadolinium-based contrast agent accumulates in the brain even in subjects without severe renal dysfunction: evaluation of autopsy brain specimens with inductively coupled plasma mass spectroscopy. Radiology 276:228-232

40. Klemm T, Duda S, Machann J, Seekamp-Rahn K, Schnieder L, Claussen CD, Schick F (2000) MR imaging in the presence of vascular stents: A systematic assessment of artifacts for various stent orientations, sequence types, and field strengths. J Magn Reson Imaging 12:606-615

41. Czervionke LF, Daniels DL, Wehrli FW, Mark LP, Hendrix LE, Strandt JA, Williams AL, Haughton VM (1988) Magnetic susceptibility artifacts in gradient-recalled echo MR imaging. AJNR Am J Neuroradiol 9:1149-1155

42. Zhang L, Song X, Dong L, Li J, Dou R, Fan Z, An J, Li D (2018) Additive value of $3 \mathrm{~T}$ cardiovascular magnetic resonance coronary angiography for detecting coronary artery disease. $\mathrm{J}$ Cardiovasc Magn Reson 20:1-8

43. Bettencourt N, Ferreira N, Chiribiri A, Schuster A, Sampaio F, Santos L, Melica B, Rodrigues A, Braga P, Teixeira M, LeiteMoreira A, Silva-Cardoso J, Portugal P, Gama V, Nagel E (2013) Additive value of magnetic resonance coronary angiography in a comprehensive cardiac magnetic resonance stress-rest protocol for detection of functionally significant coronary artery disease a pilot study. Circ Cardiovasc Imaging 6:730-738

44. Yoon YE, Kitagawa K, Kato S, Ishida M, Nakajima H, Kurita T, Ito M, Sakuma H (2012) Prognostic value of coronary magnetic resonance angiography for prediction of cardiac events in patients with suspected coronary artery disease. J Am Coll Cardiol 60:2316-2322

45. Spuentrup E, Manning WJ, Botnar RM, Kissinger KV, Stuber M (2002) Impact of navigator timing on free-breathing submillimeter 3D coronary magnetic resonance angiography. Magn Reson Med 47:196-201

46. Bhat H, Ge L, Nielles-Vallespin S, Zuehlsdorff S, Li D (2011) $3 \mathrm{D}$ radial sampling and $3 \mathrm{D}$ affine transform-based respiratory motion correction technique for free-breathing whole-heart coronary MRA with $100 \%$ imaging efficiency. Magn Reson Med 65:1269-1277

47. Hu P, Chuang ML, Ngo LH, Stoeck CT, Peters DC, Kissinger KV, Goddu B, Goepfert LA, Manning WJ, Nezafat R (2010) Coronary MR imaging: Effect of timing and dose of isosorbide dinitrate administration. Radiology 254:401-409

48. Heer T, Reiter S, Trißler M, Höfling B, von KnobelsdorffBrenkenhoff F, Pilz G (2017) Effect of nitroglycerin on the performance of MR coronary angiography. J Magn Reson Imaging 45:1419-1428

49. Deshpande VS, Shea SM, Laub G, Simonetti OP, Finn JP, Li D (2001) 3D magnetization-prepared true-FISP: a new technique for imaging coronary arteries. Magn Reson Med 46:494-502

50. Bi X, Deshpande V, Simonetti O, Laub G, Li D (2005) Threedimensional breathhold SSFP coronary MRA: a comparison between 1.5T and 3.0T. J Magn Reson Imaging 22:206-212

51. Haase A, Frahm J, Matthaei D, Hänicke W, Merboldt K-D (1986) FLASH imaging: rapid NMR imaging using low flipangle pulses. 1986. J Magn Reson 67:258-266

52. Liu X, Bi X, Huang J, Jerecic R, Carr J, Li D (2008) Contrastenhanced whole-heart coronary magnetic resonance angiography at 3.0 T. Invest Radiol 43:663-668

53. Kaul MG, Stork A, Bansmann PM, Nolte-Ernsting C, Lund GK, Weber C, Adam G (2004) Evaluation of balanced steadystate free precession (TrueFISP) and K-space segmented gradient echo sequences for 3D coronary MR angiography with navigator gating at 3 Tesla. RoFo Fortschritte auf dem Gebiet der Rontgenstrahlen und der Bildgeb Verfahren 176:1560-1565

54. Sommer T, Hackenbroch M, Hofer U, Schmiedel A, Willinek WA, Flacke S, Gieseke J, Träber F, Fimmers R, Litt H, Schild $\mathrm{H}$ (2005) Coronary MR angiography at $3.0 \mathrm{~T}$ versus that at 1.5 $\mathrm{T}$ : initial results in patients suspected of having coronary artery disease. Radiology 234:718-725

55. Brittain JH, Hu BS, Wright GA, Meyer CH, Macovski A, Nishimura DG (1995) Coronary angiography with magnetization-prepared T2 contrast. Magn Reson Med 33:689-696

56. Botnar RM, Stuber M, Danias PG, Kissinger KV, Manning WJ (1999) Improved coronary artery definition with T2-weighted, free-breathing, three-dimensional coronary MRA. Circulation 99:3139-3148

57. Nezafat M, Henningsson M, Ripley DP, Dedieu N, Greil G, Greenwood JP, Börnert P, Plein S, Botnar RM (2016) Coronary MR angiography at 3T: fat suppression versus water-fat separation. MAGMA 29:733-738

58. Bastiaansen JAM, Stuber M (2018) Flexible water excitation for fat-free MRI at 3T using lipid insensitive binomial offresonant RF excitation (LIBRE) pulses. Magn Reson Med 79:3007-3017

59. Bastiaansen JAM, van Heeswijk RB, Stuber M, Piccini D (2019) Noncontrast free-breathing respiratory self-navigated coronary artery cardiovascular magnetic resonance angiography at $3 \mathrm{~T}$ using lipid insensitive binomial off-resonant excitation (LIBRE). J Cardiovasc Magn Reson 21:38

60. Koktzoglou I, Edelman RR (2018) Radial fast interrupted steadystate (FISS) magnetic resonance imaging. Magn Reson Med 79:2077-2086

61. Bastiaansen JAM, Piccini D, Di Sopra L, Roy CW, Heerfordt J, Edelman RR, Koktzoglou I, Yerly J, Stuber M (2020) Natively fat-suppressed 5D whole-heart MRI with a radial free-running fast-interrupted steady-state (FISS) sequence at 1.5T and 3T. Magn Reson Med 83:45-55

62. Mistretta CA, Wieben O, Velikina J, Block W, Perry J, Wu Y, Johnson K, Wu Y (2006) Highly constrained backprojection for time-resolved MRI. Magn Reson Med 55:30-40 
63. Fessler JA, Sutton BP (2003) Nonuniform fast Fourier transforms using min-max interpolation. IEEE Trans Signal Process $51: 560-574$

64. Smith DS, Sengupta S, Smith SA, Brian Welch E (2019) Trajectory optimized NUFFT: faster non-Cartesian MRI reconstruction through prior knowledge and parallel architectures. Magn Reson Med 81:2064-2071

65. Lustig M, Pauly JM (2010) SPIRiT: Iterative self-consistent parallel imaging reconstruction from arbitrary k-space. Magn Reson Med 64:457-471

66. Nam S, Akçakaya M, Basha T, Stehning C, Manning WJ, Tarokh V, Nezafat R (2013) Compressed sensing reconstruction for whole-heart imaging with 3D radial trajectories: a graphics processing unit implementation. Magn Reson Med 69:91-102

67. Liu J, Saloner D (2014) Accelerated MRI with CIRcular Cartesian UnderSampling (CIRCUS): a variable density Cartesian sampling strategy for compressed sensing and parallel imaging. Quant Imaging Med Surg 4:57-67

68. Prieto C, Doneva M, Usman M, Henningsson M, Greil G, Schaeffter T, Botnar RM (2015) Highly efficient respiratory motion compensated free-breathing coronary MRA using golden-step Cartesian acquisition. J Magn Reson Imaging 41:738-746

69. Bustin A, Ginami G, Cruz G, Correia T, Ismail TF, Rashid I, Neji R, Botnar RM, Prieto C (2019) Five-minute whole-heart coronary MRA with sub-millimeter isotropic resolution, 100\% respiratory scan efficiency, and 3D-PROST reconstruction. Magn Reson Med 81:102-115

70. Pipe JG (1999) Motion correction with PROPELLER MRI: Application to head motion and free-breathing cardiac imaging. Magn Reson Med 42:963-969

71. Feng L, Axel L, Chandarana H, Block KT, Sodickson DK, Otazo R (2016) XD-GRASP: Golden-angle radial MRI with reconstruction of extra motion-state dimensions using compressed sensing. Magn Reson Med 75:775-788

72. Haji-Valizadeh H, Collins JD, Aouad PJ, Serhal AM, Lindley MD, Pang J, Naresh NK, Carr JC, Kim D (2019) Accelerated, free-breathing, noncontrast, electrocardiograph-triggered, thoracic MR angiography with stack-of-stars k-space sampling and GRASP reconstruction. Magn Reson Med 81:524-532

73. Larson AC, White RD, Laub G, McVeigh ER, Li D, Simonetti OP (2004) Self-gated cardiac cine MRI. Magn Reson Med 51:93-102

74. Liu J, Spincemaille P, Codella NCF, Nguyen TD, Prince MR, Wang Y (2010) Respiratory and cardiac self-gated free-breathing cardiac CINE imaging with multiecho 3D hybrid radial SSFP acquisition. Magn Reson Med 63:1230-1237

75. Stehning C, Börnert P, Nehrke K, Eggers H, Stuber M (2005) Free-breathing whole-heart coronary MRA with 3D radial SSFP and self-navigated image reconstruction. Magn Reson Med 54:476-480

76. Winkelmann S, Schaeffter T, Koehler T, Eggers H, Doessel O (2007) An optimal radial profile order based on the golden ratio for time-resolved MRI. IEEE Trans Med Imaging 26:68-76

77. Feng L, Benkert T, Block KT, Sodickson DK, Otazo R, Chandarana H (2017) Compressed sensing for body MRI. J Magn Reson Imaging 45:966-987

78. Feng L, Grimm R, Block KT, Chandarana H, Kim S, Xu J, Axel L, Sodickson DK, Otazo R (2014) Golden-angle radial sparse parallel MRI: combination of compressed sensing, parallel imaging, and golden-angle radial sampling for fast and flexible dynamic volumetric MRI. Magn Reson Med 72:707-717

79. Chandarana H, Block TK, Rosenkrantz AB, Lim RP, Kim D, Mossa DJ, Babb JS, Kiefer B, Lee VS (2011) Free-breathing radial 3D fat-suppressed T1-weighted gradient echo sequence: a viable alternative for contrast-enhanced liver imaging in patients unable to suspend respiration. Invest Radiol 46:648-653
80. Pruessmann KP, Weiger M, Scheidegger MB, Boesiger P (1999) SENSE: sensitivity encoding for fast MRI. Magn Reson Med 42:952-962

81. Sodickson DK, Manning WJ (1997) Simultaneous acquisition of spatial harmonics (SMASH): fast imaging with radiofrequency coil arrays. Magn Reson Med 38:591-603

82. Griswold MA, Jakob PM, Heidemann RM, Nittka M, Jellus V, Wang J, Kiefer B, Haase A (2002) Generalized autocalibrating partially parallel acquisitions (GRAPPA). Magn Reson Med 47:1202-1210

83. Deshmane A, Gulani V, Griswold MA, Seiberlich N (2012) Parallel MR imaging. J Magn Reson Imaging 36:55-72

84. Gharib AM, Abd-Elmoniem KZ, Ho VB, Födi E, Herzka DA, Ohayon J, Stuber M, Pettigrew RI (2012) The feasibility of 350 $\mu \mathrm{m}$ spatial resolution coronary magnetic resonance angiography at $3 \mathrm{~T}$ in humans. Invest Radiol 47:339-345

85. Lustig M, Donoho D, Pauly JM (2007) Sparse MRI: The application of compressed sensing for rapid MR imaging. Magn Reson Med 58:1182-1195

86. Lustig M, Donoho D (2008) Compressed sensing MRI. Signal Process Mag 72-82

87. Akçakaya M, Basha TA, Goddu B, Goepfert LA, Kissinger KV, Tarokh V, Manning WJ, Nezafat R (2011) Low-dimensionalstructure self-learning and thresholding: regularization beyond compressed sensing for MRI reconstruction. Magn Reson Med 66:756-767

88. Otazo R, Kim D, Axel L, Sodickson DK (2010) Combination of compressed sensing and parallel imaging for highly accelerated first-pass cardiac perfusion MRI. Magn Reson Med 64:767-776

89. Uecker M, Lai P, Murphy MJ, Virtue P, Elad M, Pauly JM, Vasanawala SS, Lustig M (2014) ESPIRiT—an eigenvalue approach to autocalibrating parallel MRI: where SENSE meets GRAPPA. Magn Reson Med 71:990-1001

90. Hollingsworth KG (2015) Reducing acquisition time in clinical MRI by data undersampling and compressed sensing reconstruction. Phys Med Biol 60:R297-R322

91. Haris K, Hedström E, Bidhult S, Testud F, Maglaveras N, Heiberg E, Hansson SR, Arheden H, Aletras AH (2017) Selfgated fetal cardiac MRI with tiny golden angle iGRASP: a feasibility study. J Magn Reson Imaging 46:207-217

92. Hyun CM, Kim HP, Lee SM, Lee S, Seo JK (2018) Deep learning for undersampled MRI reconstruction. Phys Med Biol 63:135007

93. Hauptmann A, Arridge S, Lucka F, Muthurangu V, Steeden JA (2018) Real-time cardiovascular MR with spatio-temporal artifact suppression using deep learning-proof of concept in congenital heart disease. Magn Reson Med 1143-1156

94. Aitken AP, Henningsson M, Botnar RM, Schaeffter T, Prieto C (2015) 100\% Efficient three-dimensional coronary MR angiography with two-dimensional beat-to-beat translational and binto-bin affine motion correction. Magn Reson Med 74:756-764

95. Addy NO, Ingle RR, Luo J, Baron CA, Yang PC, Hu BS, Nishimura DG (2017) 3D image-based navigators for coronary MR angiography. Magn Reson Med 77:1874-1883

96. Piccini D, Littmann A, Nielles-Vallespin S, Zenge MO (2012) Respiratory self-navigation for whole-heart bright-blood coronary MRI: Methods for robust isolation and automatic segmentation of the blood pool. Magn Reson Med 68:571-579

97. Piccini D, Bonanno G, Ginami G, Littmann A, Zenge MO, Stuber $M$ (2016) Is there an optimal respiratory reference position for self-navigated whole-heart coronary MR angiography? J Magn Reson Imaging 43:426-433

98. Pang J, Bhat H, Sharif B, Fan Z, Thomson LEJ, Labounty T, Friedman JD, Min J, Berman DS, Li D (2014) Whole-heart coronary MRA with $100 \%$ respiratory gating efficiency: 
self-navigated three-dimensional retrospective image-based motion correction (TRIM). Magn Reson Med 71:67-74

99. Greenspan H, Peled S, Oz G, Kiryati N (2001) MRI inter-slice reconstruction using super-resolution. Lect Notes Comput Sci (including Subser Lect Notes Artif Intell Lect Notes Bioinformatics) 2208:1204-1206

100. Rueda A, Malpica N, Romero E (2013) Single-image superresolution of brain MR images using overcomplete dictionaries. Med Image Anal 17:113-132

101. Chen Y, Xie Y, Zhou Z, Shi F, Christodoulou AG, Li D (2018) Brain MRI super resolution using 3D deep densely connected neural networks. Proc-Int Symp Biomed Imaging 2018-April:739-742

102. Chen Y, Shi F, Christodoulou AG, Xie Y, Zhou Z, Li D (2018) Efficient and accurate MRI super-resolution using a generative adversarial network and 3D multi-level densely connected network. Med Image Comput Comput Assist Interv 91-99

103. Chen Y, Shaw JL, Xie Y, Li D, Christodoulou AG (2019) Deep learning within a priori temporal feature spaces for large-scale dynamic MR image reconstruction: application to 5-D cardiac MR Multitasking 1-9

104. Ishida M, Nakayama R, Uno M, Ito T, Goto Y, Ichikawa Y, Nagata M, Kitagawa K, Nakamori S, Dohi K, Ito M, Sakuma H (2014) Learning-based super-resolution technique significantly improves detection of coronary artery stenoses on $1.5 \mathrm{~T}$ wholeheart coronary MRA. J Cardiovasc Magn Reson 16:P218

105. Esses SJ, Lu X, Zhao T, Shanbhogue K, Dane B, Bruno M, Chandarana $H$ (2018) Automated image quality evaluation of T2-weighted liver MRI utilizing deep learning architecture. J Magn Reson Imaging 47:723-728

106. Nakanishi R, Sankaran S, Grady L, Malpeso J, Yousfi R, Osawa K, Ceponiene I, Nazarat N, Rahmani S, Kissel K, Jayawardena E, Dailing C, Zarins C, Koo BK, Min JK, Taylor CA, Budoff MJ (2018) Automated estimation of image quality for coronary computed tomographic angiography using machine learning. Eur Radiol 28:4018-4026

107. Gudbjartsson H, Patz S (1995) The Rician distribution of noisy MRI data. Magn Reson Med 34:910-914

108. Manjón JV, Coupé P, Martí-Bonmatí L, Collins DL, Robles M (2010) Adaptive non-local means denoising of MR images with spatially varying noise levels. J Magn Reson Imaging 31:192-203

109. Dabov K, Foi A, Katkovnik V, Egiazarian K (2007) Image denoising by sparse 3-D transform-domain collaborative filtering. IEEE Trans Image Process 16:2080-2095

110. Gupta SM (2018) A review and comprehensive comparison of image de-noising techniques. In: 2017 6th Int Conf Reliab Infocom Technol Optim Trends Futur Dir ICRITO 2017 2018Janua, pp 624-629

111. Zhu B, Liu JZ, Cauley SF, Rosen BR, Rosen MS (2018) Image reconstruction by domain-transform manifold learning. Nature 555:487-492

112. Han Y, Ye JC (2018) k-space deep learning for accelerated. MRI. 1-11

113. Chen Y, Pock T (2017) Trainable nonlinear reaction diffusion: a flexible framework for fast and effective image restoration. IEEE Trans Pattern Anal Mach Intell 39:1256-1272

114. Zhang K, Zuo W, Chen Y, Meng D, Zhang L (2017) Beyond a Gaussian denoiser: residual learning of deep CNN for image denoising. IEEE Trans Image Process 26:3142-3155

115. Isogawa K, Ida T, Shiodera T, Takeguchi T (2018) Deep shrinkage convolutional neural network for adaptive noise reduction. IEEE Signal Process Lett 25:224-228

116. Kidoh M, Shinoda K, Kitajima M, Isogawa K, Nambu M, Uetani H, Morita K, Nakaura T, Tateishi M, Yamashita YY, Yamashita YY (2019) Deep learning based noise reduction for brain MR imaging: tests on phantoms and healthy volunteers. Magn Reson Med Sci. https://doi.org/10.2463/mrms. mp.2019-0018

117. Etienne A, Botnar RM, Van Muiswinkel AMC, Boesiger P, Manning WJ, Stuber M (2002) "Soap-Bubble" visualization and quantitative analysis of 3D coronary magnetic resonance angiograms. Magn Reson Med 48:658-666

118. Soleimanifard S, Schär M, Hays AG, Weiss RG, Stuber M, Prince JL (2012) Vessel centerline tracking and boundary segmentation in coronary MRA with minimal manual interaction. In: Proc-Int symp biomed imaging, pp 1417-1420

119. Yonezawa M, Nagata M, Kitagawa K, Kato S, Yoon Y, Nakajima H, Nakamori S, Sakuma H, Hatakenaka M, Honda H (2014) Quantitative analysis of 1.5-T whole-heart coronary MR angiograms obtained with 32-channel cardiac coils: a comparison with conventional quantitative coronary angiography. Radiology 271:356-364

120. Kim SM, Choi J-H, Choe YH (2016) Coronary artery total occlusion: MR angiographic imaging findings and success rates of percutaneous coronary intervention according to intraluminal signal intensity patterns. Radiology 279:84-92

121. Kawasaki T, Koga S, Koga N, Noguchi T, Tanaka H, Koga H, Serikawa T, Orita Y, Ikeda S, Mito T, Goto Y, Shintani Y, Tanaka A, Fukuyama T (2009) Characterization of hyperintense plaque with noncontrast $\mathrm{T}(1)$-weighted cardiac magnetic resonance coronary plaque imaging: comparison with multislice computed tomography and intravascular ultrasound. JACC Cardiovasc Imaging 2:720-728

122. Noguchi T, Yamada N, Higashi M, Goto Y, Naito H (2011) High-intensity signals in carotid plaques on T1-weighted magnetic resonance imaging predict coronary events in patients with coronary artery disease. J Am Coll Cardiol 58:416-422

123. Oshita A, Kawakami H, Kito K, Kono Y, Miyoshi T, Matsuoka $\mathrm{H}$ (2018) Clinical utility of non-contrast T1-weighted magnetic resonance imaging in percutaneous coronary intervention: a case report. J Cardiol Cases 19:9-11

124. Raman SV, Winner MW, Tran T, Velayutham M, Simonetti OP, Baker PB, Olesik J, McCarthy B, Ferketich AK, Zweier JL (2008) In Vivo Atherosclerotic plaque characterization using magnetic susceptibility distinguishes symptom-producing plaques. JACC Cardiovasc Imaging 1:49-57

125. Sharkey-Toppen TP, Tewari AK, Raman SV (2014) Iron and atherosclerosis: Nailing down a novel target with magnetic resonance. J Cardiovasc Transl Res 7:533-542

126. Károlyi M, Seifarth H, Liew G, Schlett CL, Maurovich-Horvat P, Stolzmann P, Dai G, Huang S, Goergen CJ, Nakano M, Otsuka F, Virmani R, Hoffmann U, Sosnovik DE (2013) Classification of coronary atherosclerotic plaques ex vivo with $\mathrm{T} 1$, T2, and ultrashort echo time CMR. JACC Cardiovasc Imaging 6:466-474

127. Chan CF, Keenan NG, Nielles-Vallespin S, Gatehouse P, Sheppard MN, Boyle JJ, Pennell DJ, Firmin DN (2010) Ultra-short echo time cardiovascular magnetic resonance of atherosclerotic carotid plaque. J Cardiovasc Magn Reson Off J Soc Cardiovasc Magn Reson 12:17

128. Yang Q, Barnes SRS, Wu Z, Neelavalli J, Hu J, Li K, Liu J, Haacke EM (2009) Imaging the vessel wall in major peripheral arteries using susceptibility-weighted imaging. J Magn Reson Imaging 30:357-365

129. Rajendran R, Minqin R, Ronald JA, Rutt BK, Halliwell B, Watt F (2012) Does iron inhibit calcification during atherosclerosis? Free Radic Biol Med 53:1675-1679

130. Sakuma H, Saeed M, Takeda K, Wendland MF, Szolar H, Shimakawa A, Foo TKE, Higgins CB (1997) Quantification volume flow velocity-encoded Cine MR imaging. AJR Am J Roentgenol 1363-1367 
131. Hood WB (1968) Regional venous drainage of the human heart. Heart 30:105-109

132. Lund GK, Wendland MF, Shimakawa A, Arheden H, Ståhlberg F, Higgins CB, Saeed M (2000) Coronary sinus flow measurement by means of velocity-encoded cine MR imaging: validation by using flow probes in dogs. Radiology 217:487-493

133. Kato S, Saito N, Nakachi T, Fukui K, Iwasawa T, Taguri M, Kosuge M, Kimura K (2017) Stress perfusion coronary flow reserve versus cardiac magnetic resonance for known or suspected CAD. J Am Coll Cardiol 70:869-879

134. Sakuma H, Kawada N, Takeda K, Higgins CB (1999) MR measurement of coronary blood flow. J Magn Reson Imaging 10:728-733

135. Van De Hoef TP, Van Lavieren MA, Damman P, Delewi R, Piek MA, Chamuleau SAJ, Voskuil M, Henriques JPS, Koch KT, De Winter RJ, Spaan JAE, Siebes M, Tijssen JGP, Meuwissen M, Piek JJ (2014) Physiological basis and long-term clinical outcome of discordance between fractional flow reserve and coronary flow velocity reserve in coronary stenoses of intermediate severity. Circ Cardiovasc Interv 7:301-311

136. Van De Hoef TP, Siebes M, Spaan JAE, Piek JJ (2015) Fundamentals in clinical coronary physiology: Why coronary flow is more important than coronary pressure. Eur Heart $\mathbf{J}$ 36:3312-3319
137. Murthy VL, Naya M, Foster CR, Hainer J, Gaber M, Di Carli G, Blankstein R, Dorbala S, Sitek A, Pencina MJ, Di Carli MF (2011) Improved cardiac risk assessment with noninvasive measures of coronary flow reserve. Circulation 124:2215-2224

138. Deng Z, Fan Z, Lee S-E, Nguyen C, Xie Y, Pang J, Bi X, Yang Q, Choi B-W, Kim J-S, Berman D, Chang H-J, Li D (2017) Noninvasive measurement of pressure gradient across a coronary stenosis using phase contrast (PC)-MRI: a feasibility study. Magn Reson Med 77:529-537

139. Dyverfeldt P, Bissell M, Barker AJ, Bolger AF, Carlhäll CJ, Ebbers T, Francios CJ, Frydrychowicz A, Geiger J, Giese D, Hope MD, Kilner PJ, Kozerke S, Myerson S, Neubauer S, Wieben O, Markl M (2015) 4D flow cardiovascular magnetic resonance consensus statement. J Cardiovasc Magn Reson 17:1-19

140. Shinoda K, Isogawa K, Nambu M, Yamashita Y, Uetani H, Kitajima M, Yamashita Y (2019) Deep learning based adaptive noise reduction in multi-contrast MR images. ISMRM 2019 Abstr

141. Mugler JP, Brookeman JR (1990) Three-dimensional magnetization-prepared rapid gradient-echo imaging (3D MP RAGE). Magn Reson Med 15:152-157

Publisher's Note Springer Nature remains neutral with regard to jurisdictional claims in published maps and institutional affiliations. 